\begin{tabular}{|c|c|c|}
\hline 000 & Georgian Scientists & 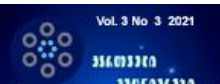 \\
\hline & 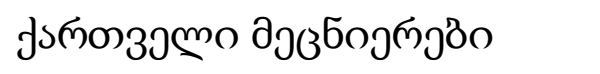 & $\begin{array}{l}\text { GEORGIAN } \\
\text { SCIENTISTS }\end{array}$ \\
\hline 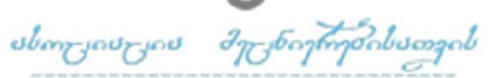 & Vol. 3 I ssue 3, 2021 & \\
\hline Association For Science & https://doi.org/10.52340/gs.2021.08.06 & 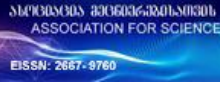 \\
\hline
\end{tabular}

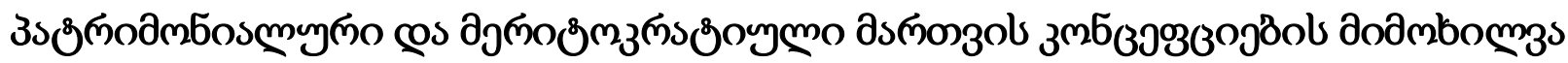 cos s6smobo
}

osวasm Rsm $330 s 60$

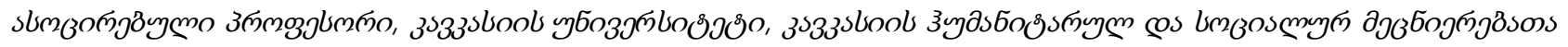

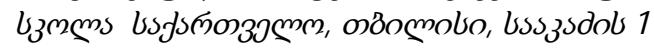

ơnल:: 593755818

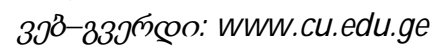

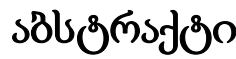

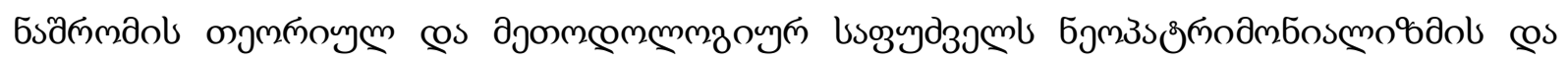

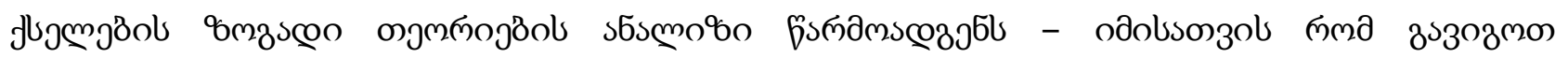

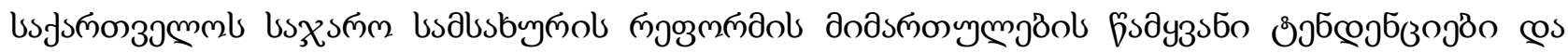

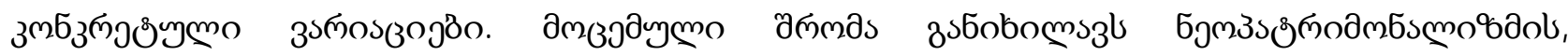

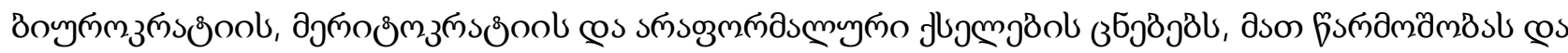

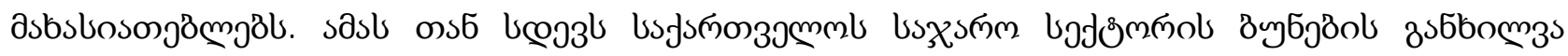

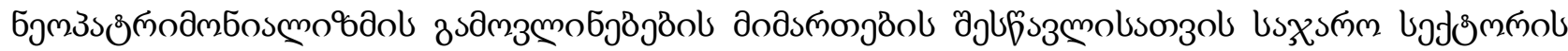

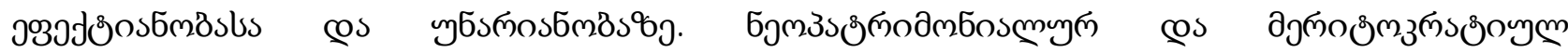

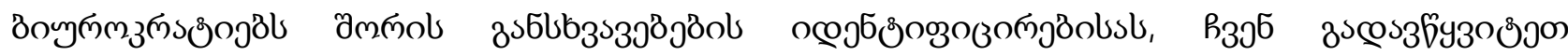

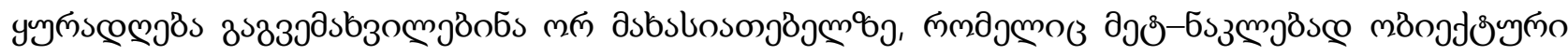

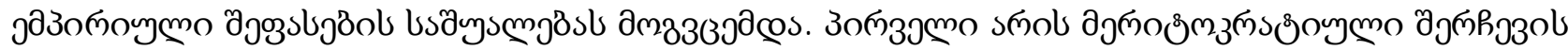

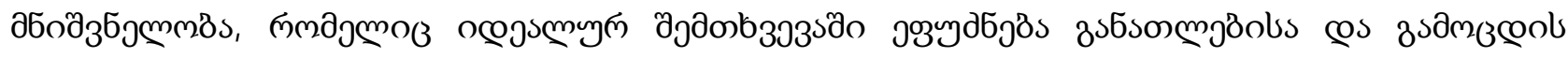

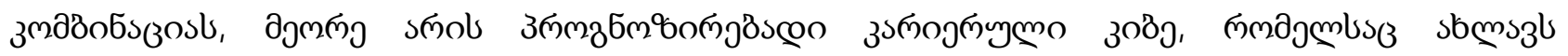

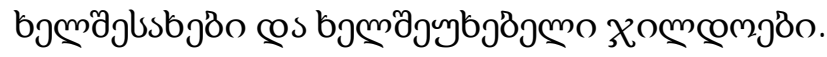

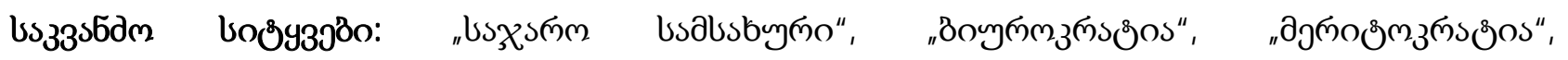

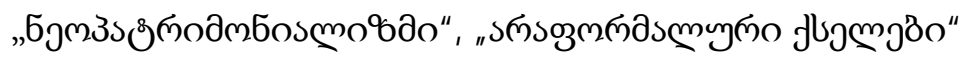




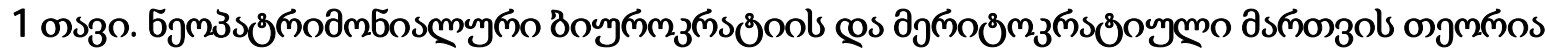

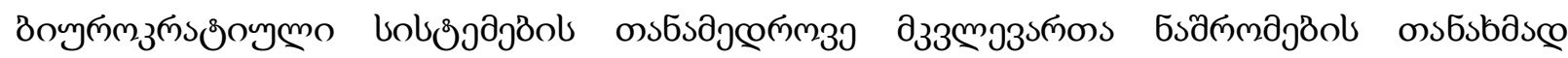

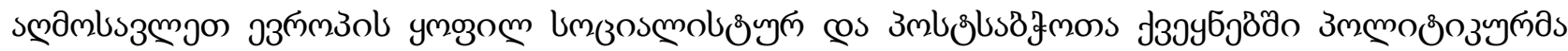

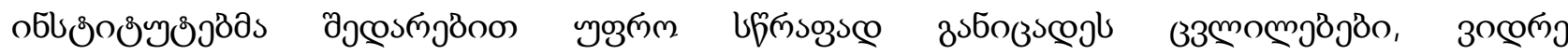

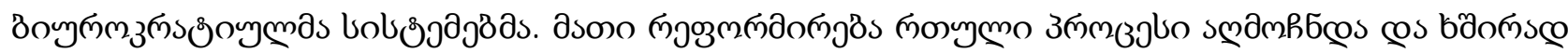

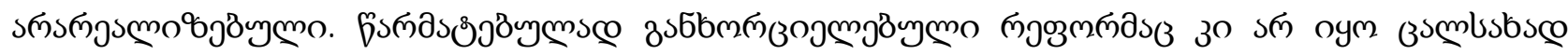

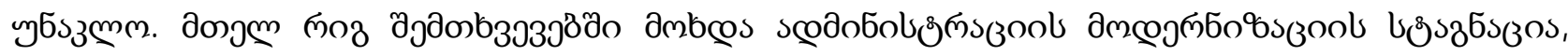

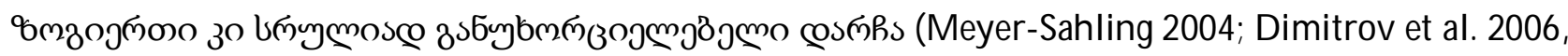
33.225-29; Verheijen 2007; Oleinik 2009).

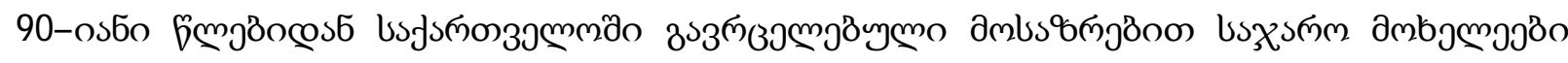

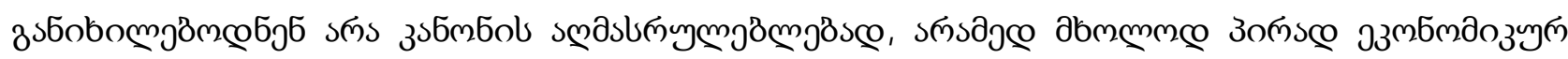

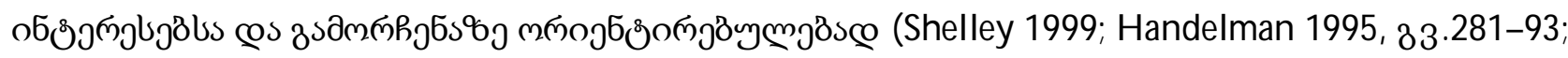
Favarel-Garrigues 2003; Bebler 2001; Taylor 2011; Gerber and Mendelson 2008; Kolennikova et al.

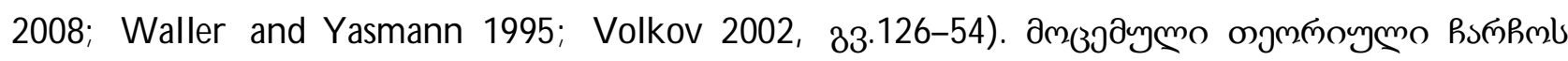

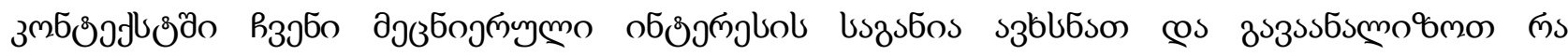

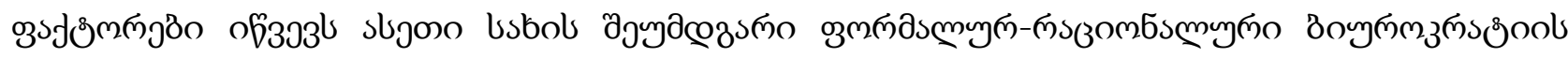

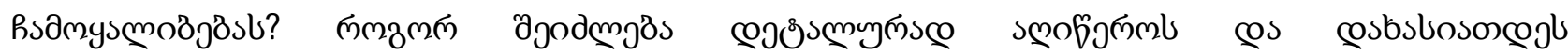

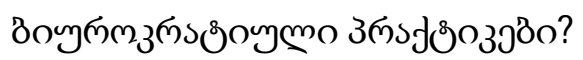

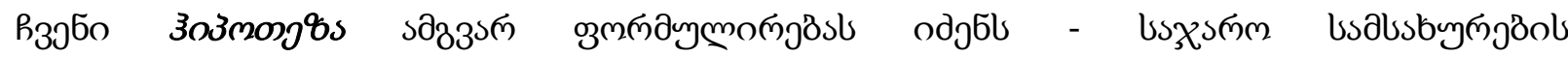

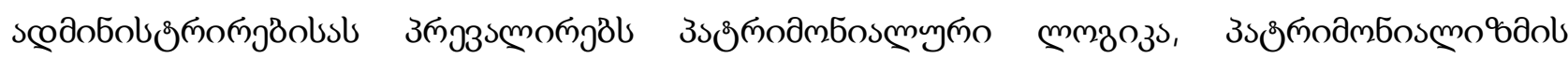

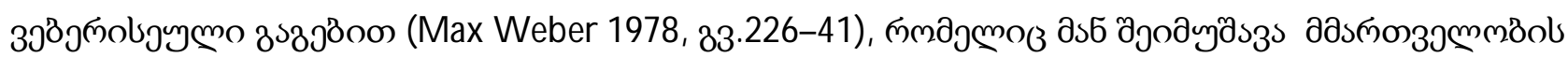

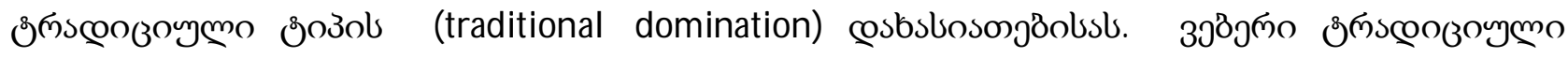

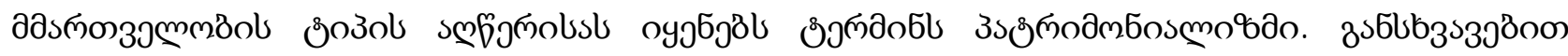

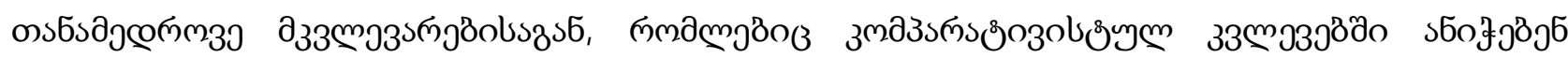

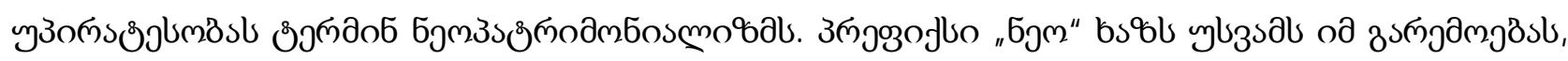

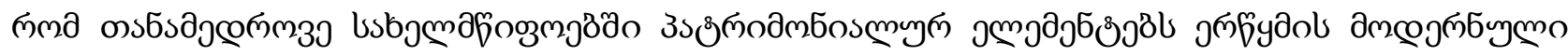

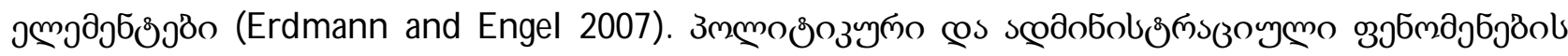

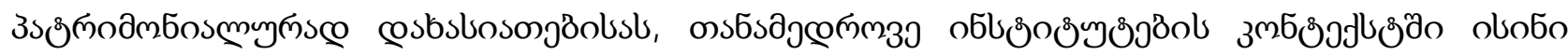

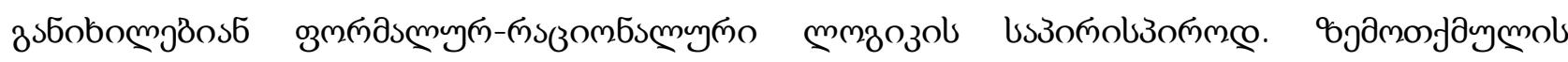

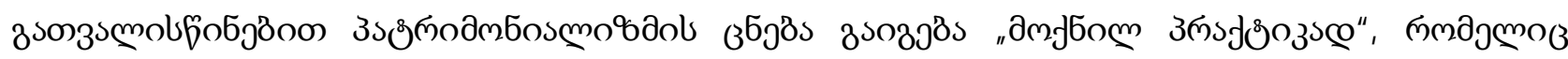

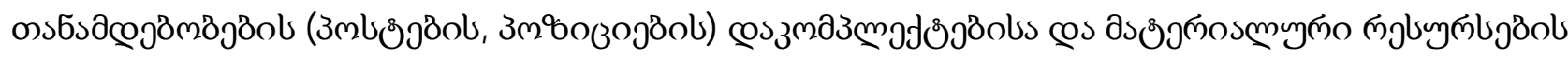

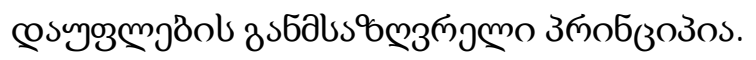

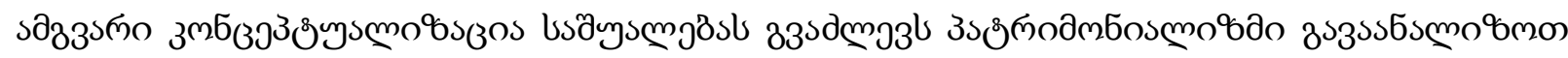

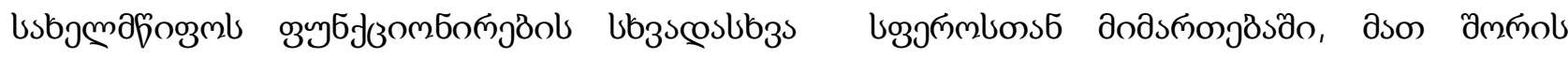

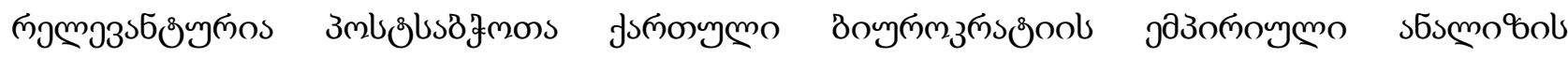

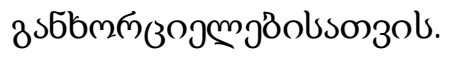




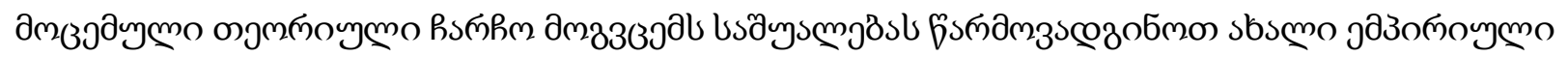

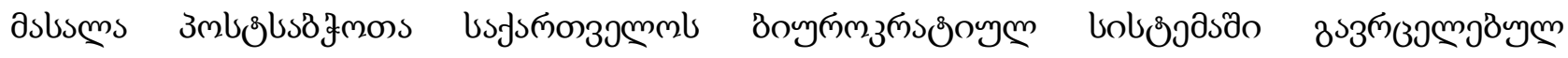

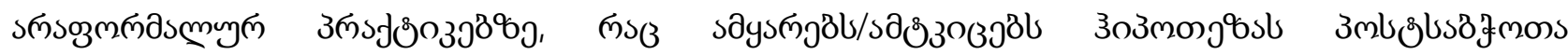

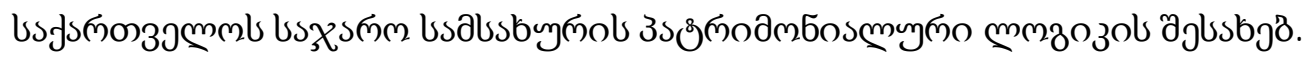

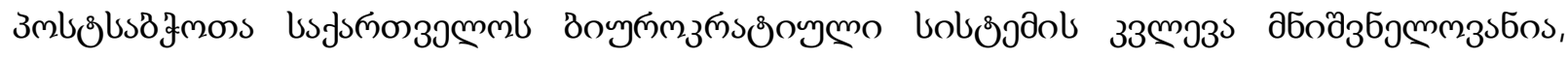

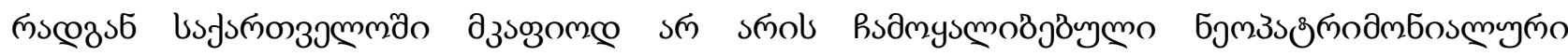

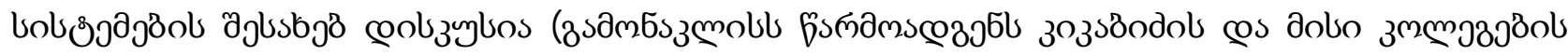
Әммдјठо (Kitschelt et al. 1999, 83.39).

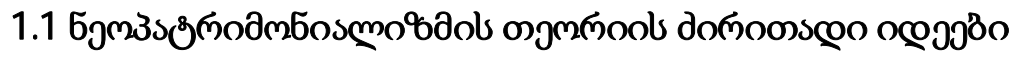

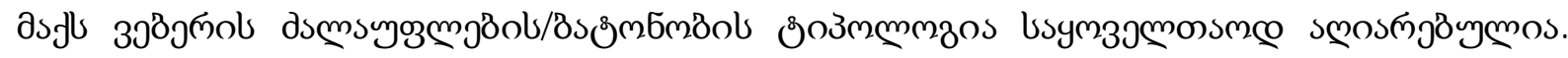

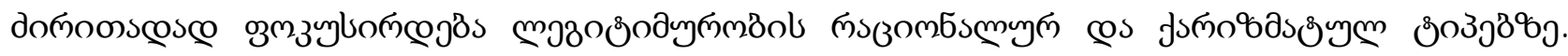

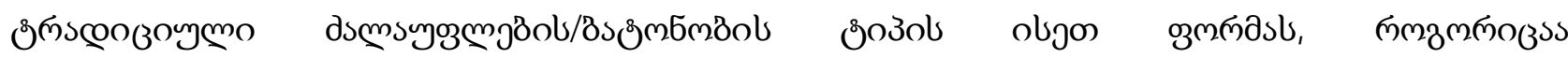

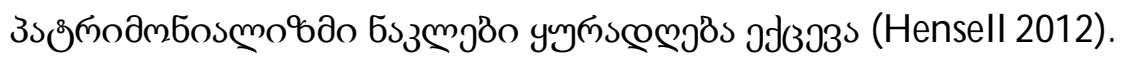

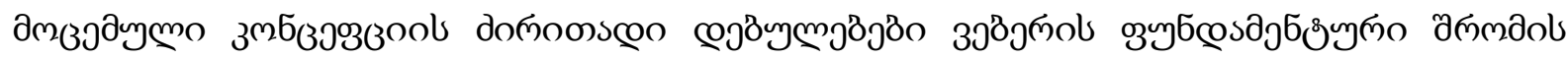

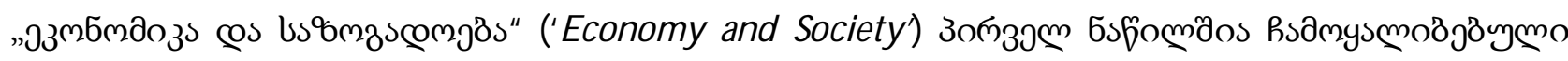

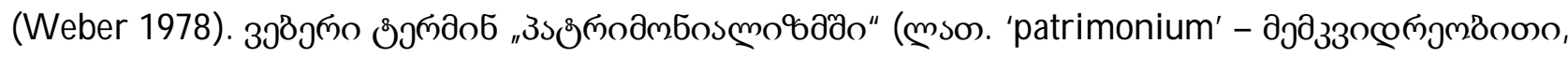

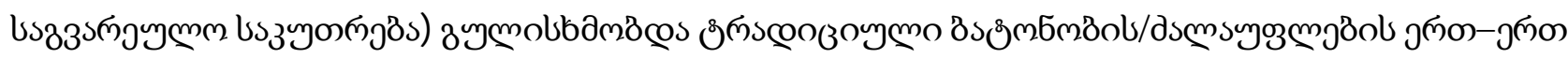

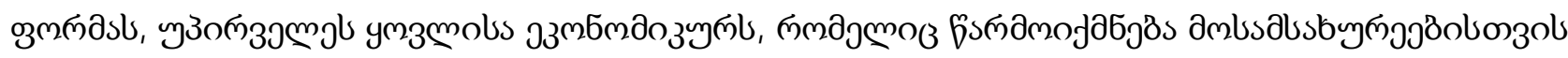

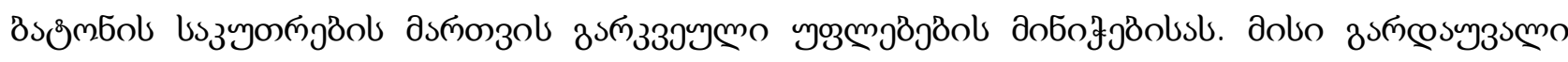

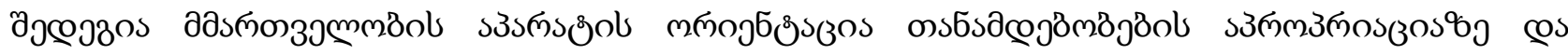

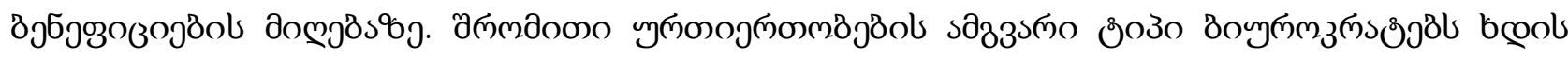

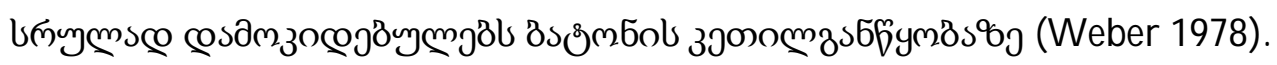

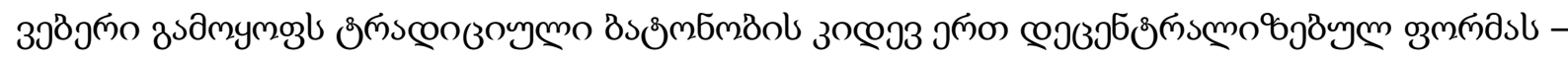

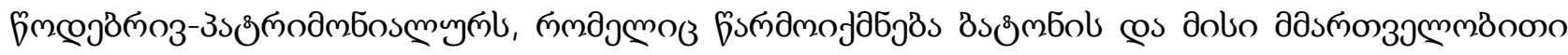

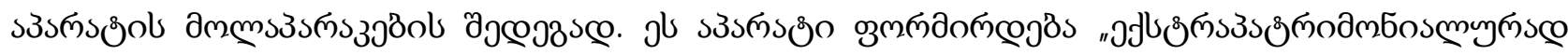

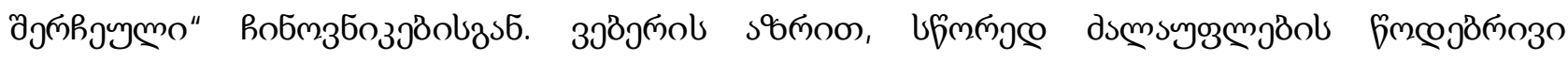

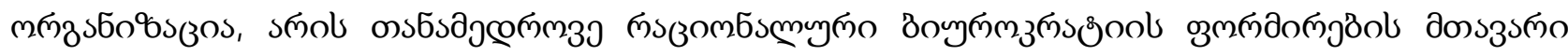

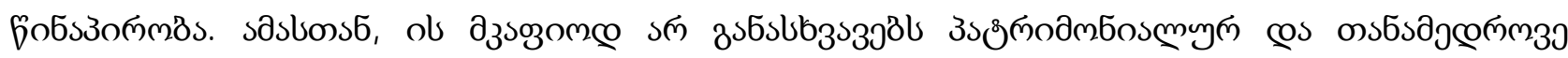

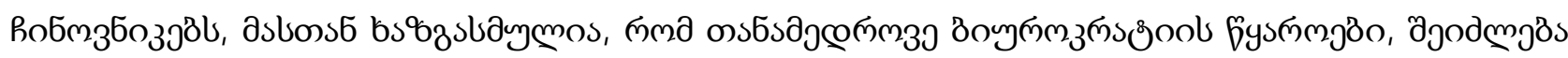

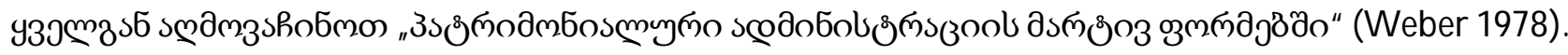

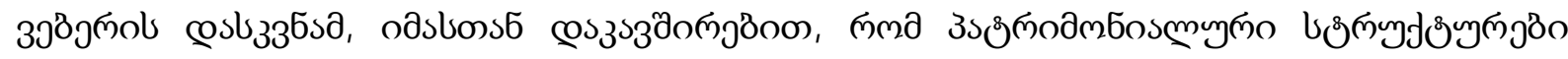

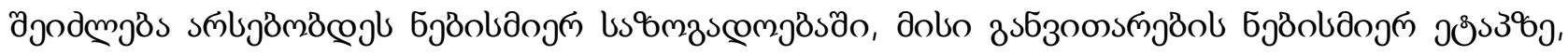

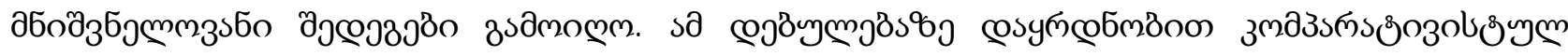

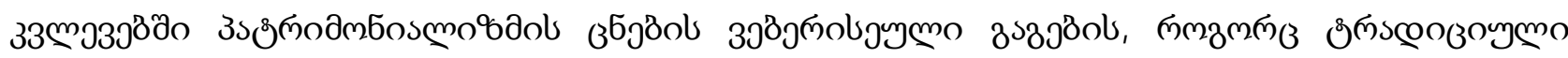

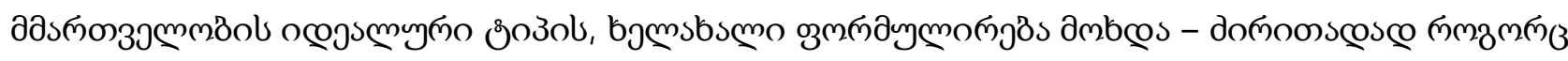

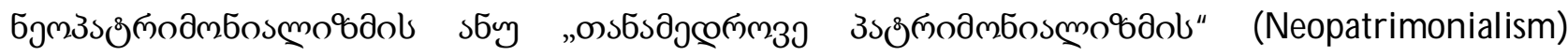
(Eisenstadt 1973). 


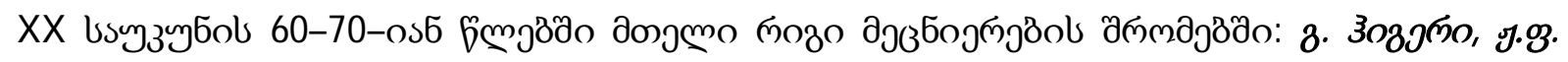

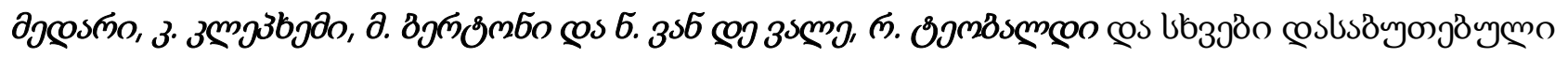

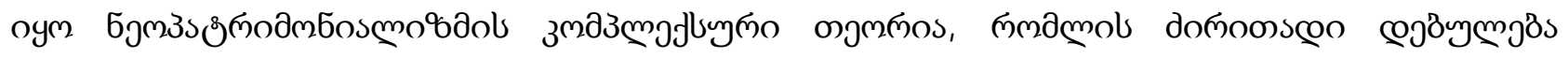

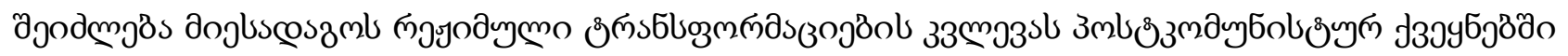

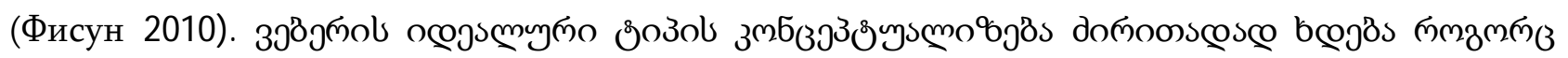

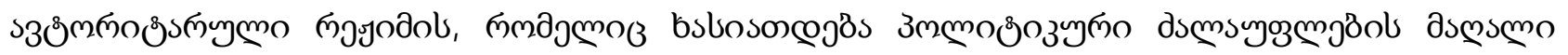

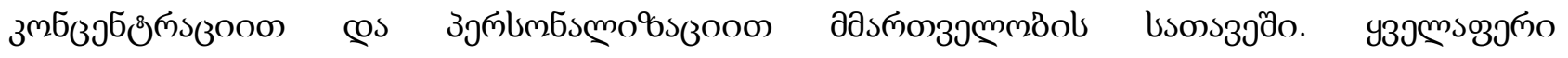

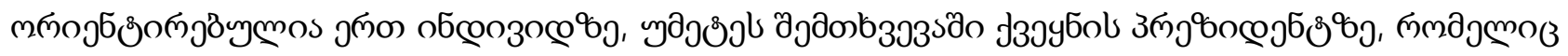

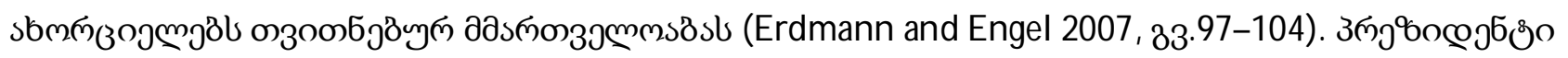

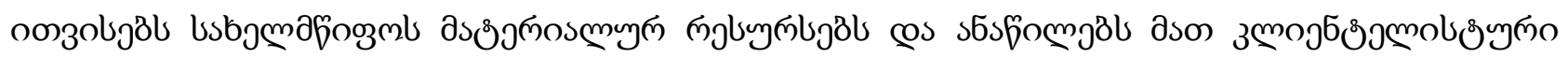

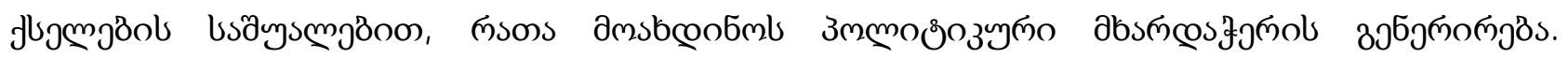

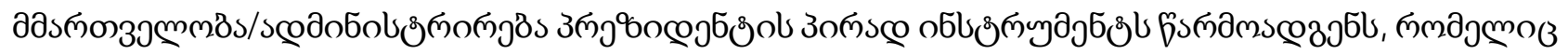

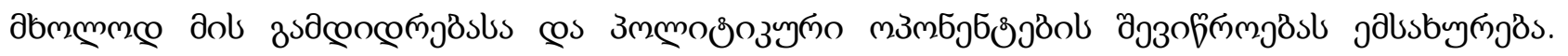

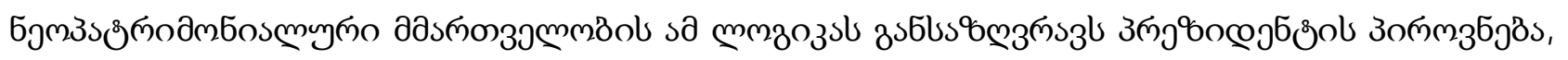

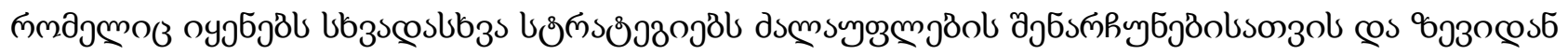

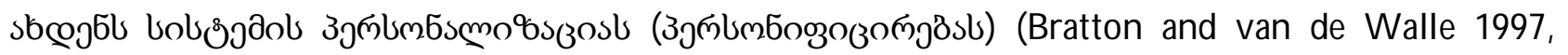
33.61-65; Chehabi and Linz 1998a, 33.7-10, 13-17; Geddes 1999, 33.121-22). sБsмоชீозупо

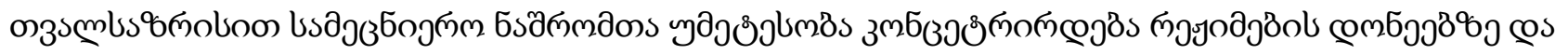

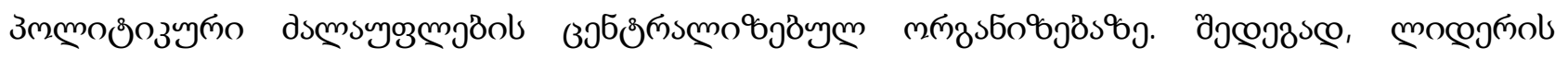

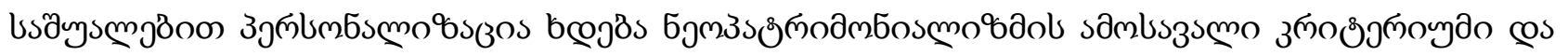

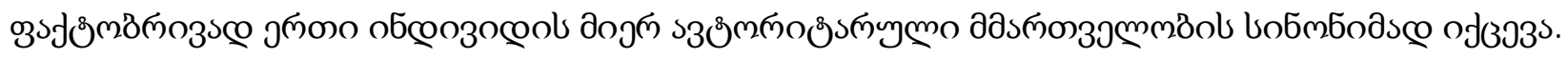

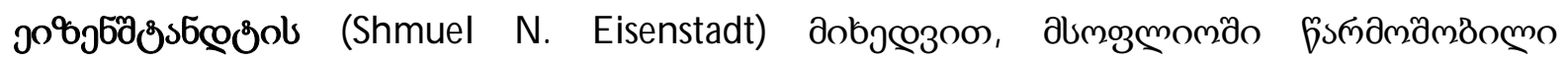

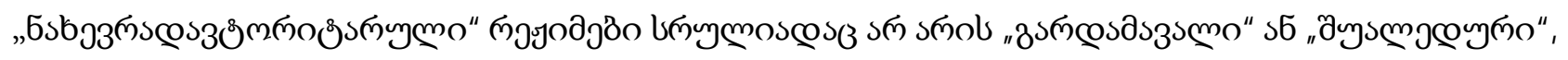

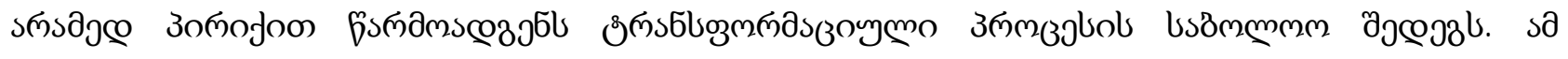

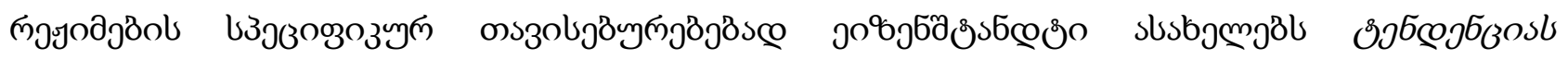

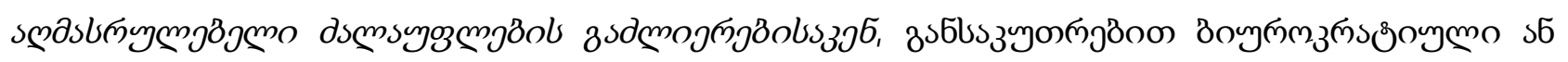

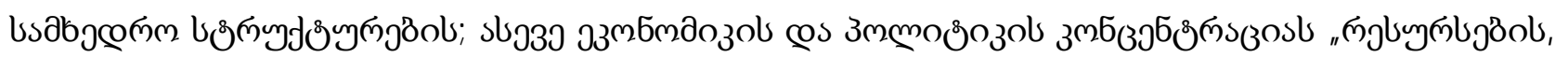

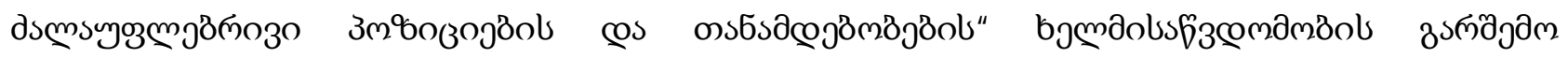
(Эйзенштадт 2002).

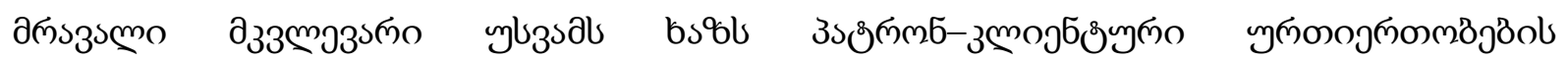

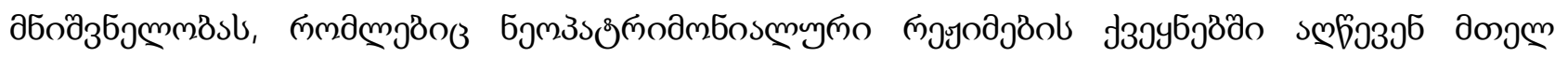

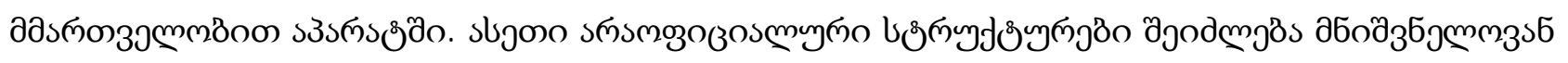

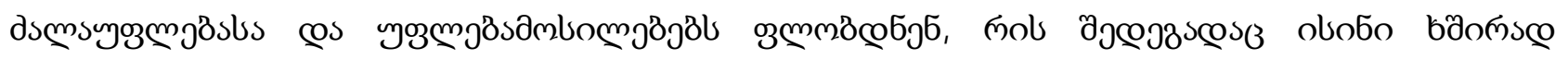

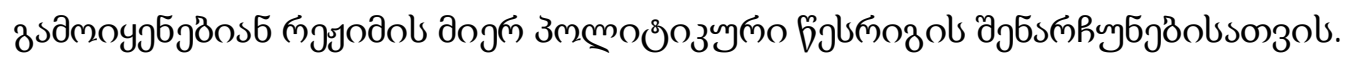

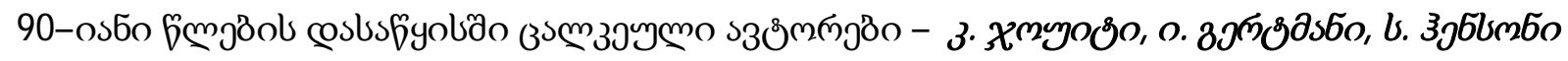

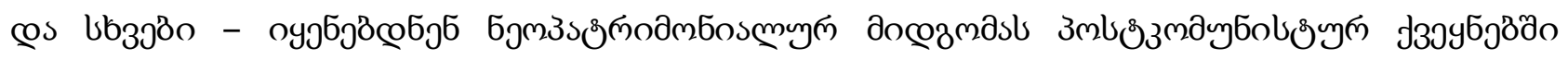

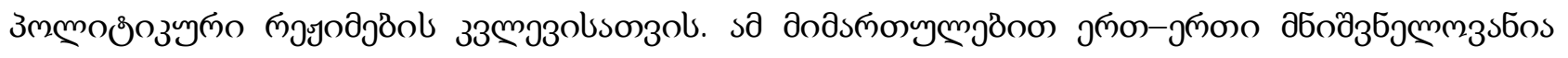

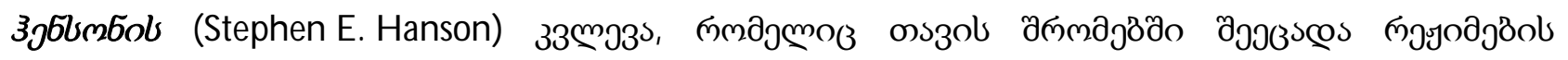




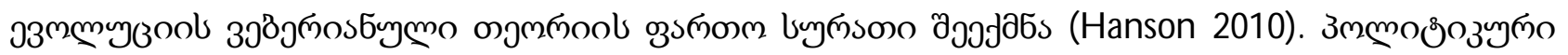

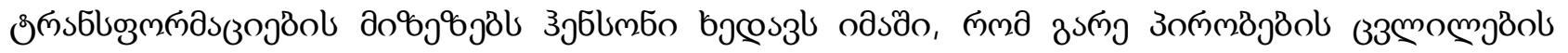

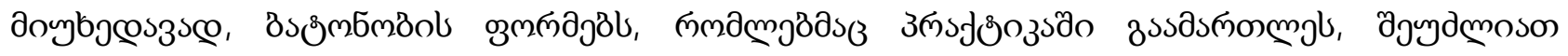

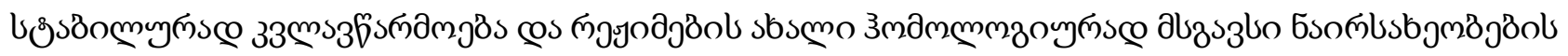

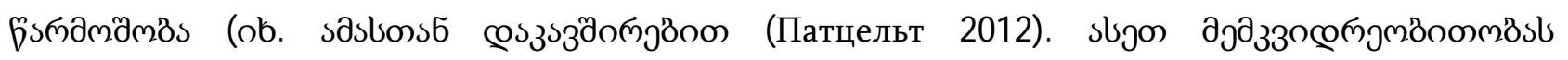

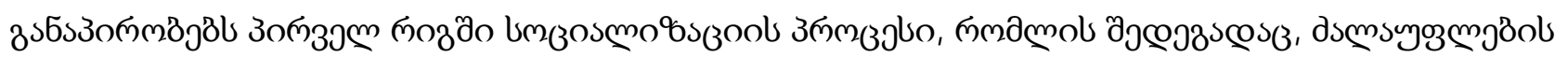

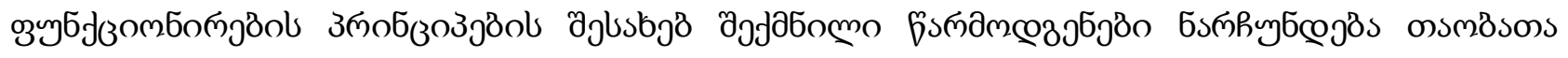

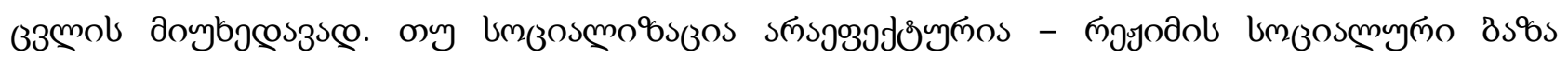

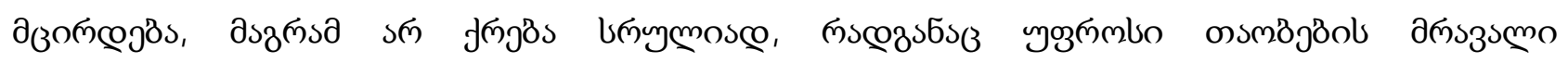

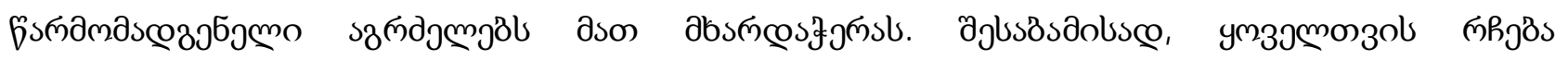

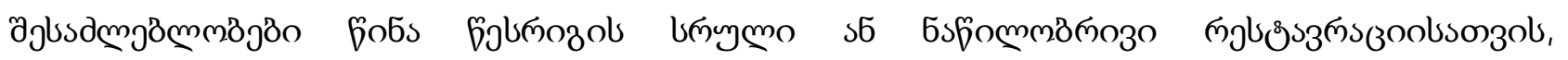

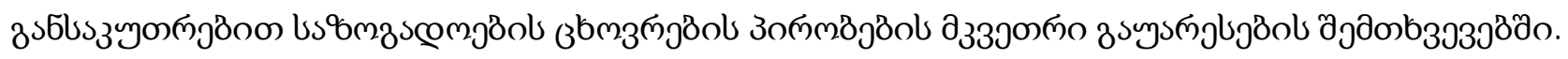

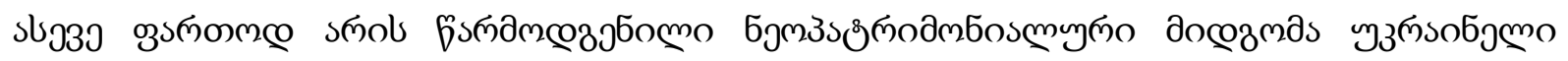

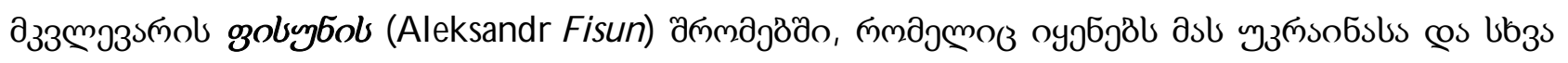

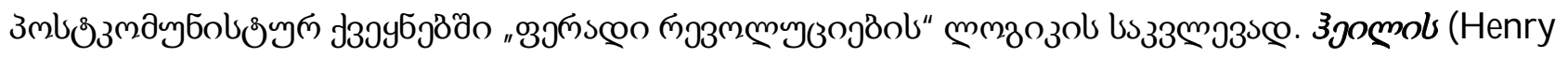

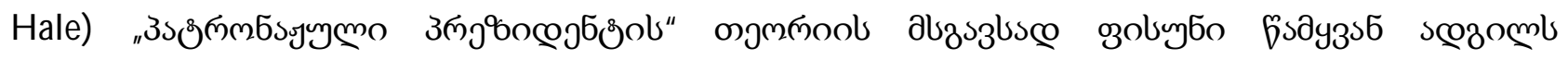

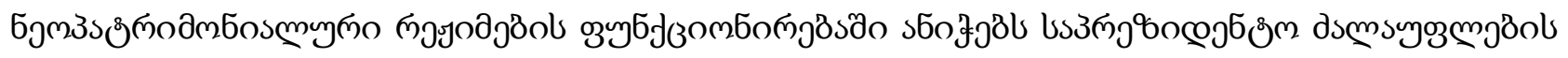

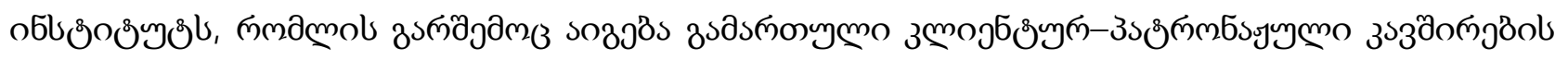

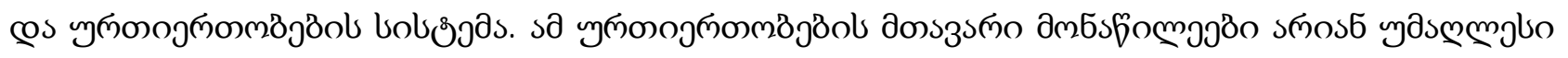

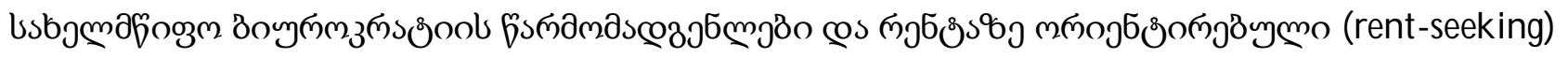

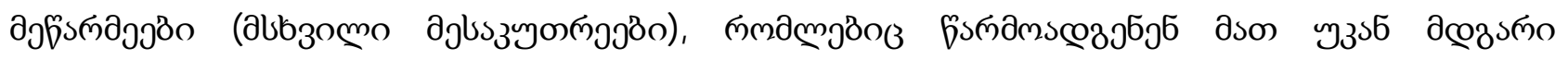

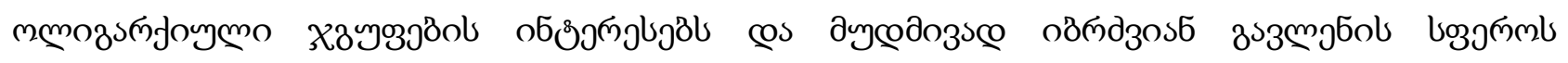

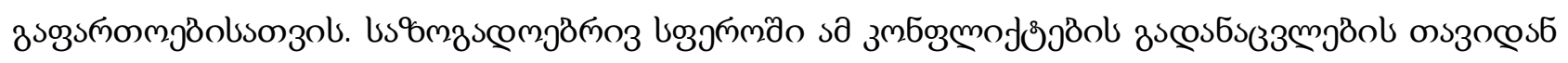

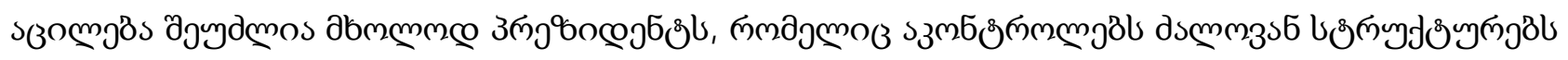

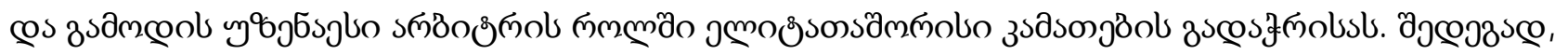

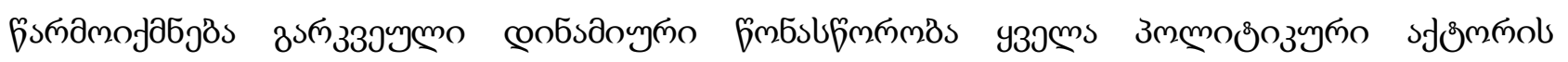

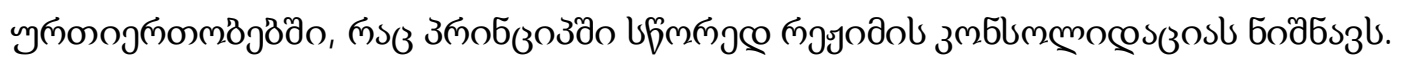

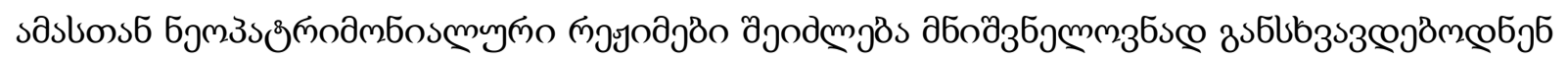

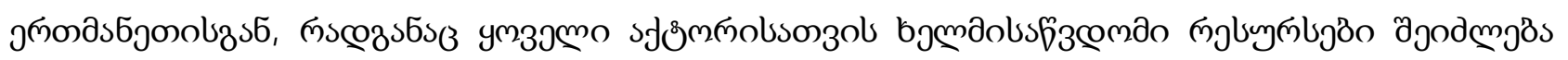

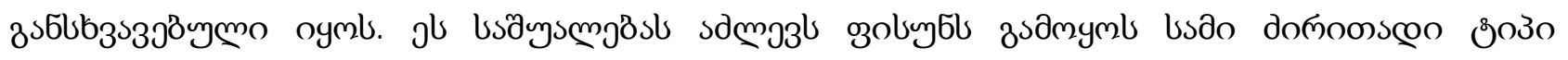

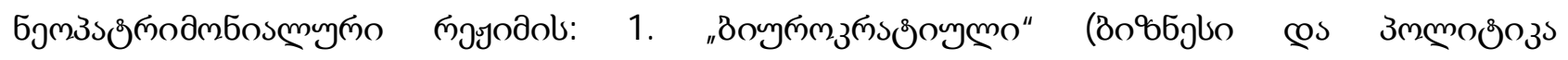

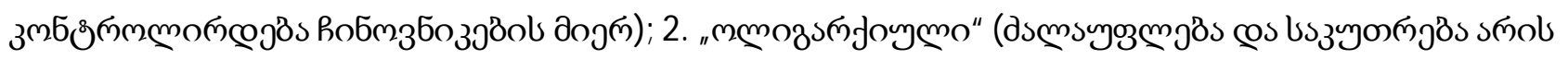

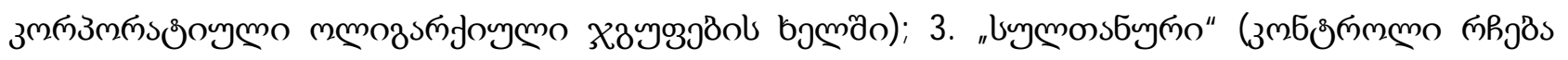

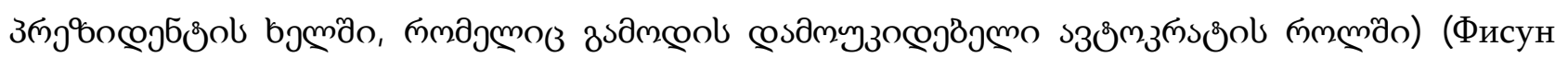
2010).

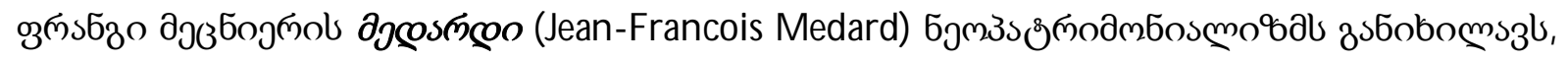

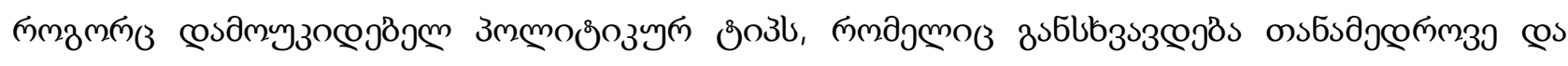

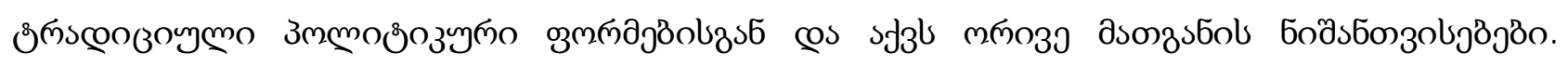




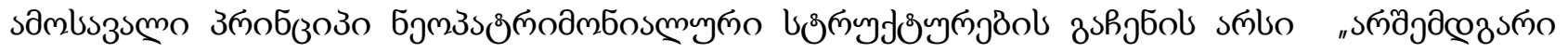

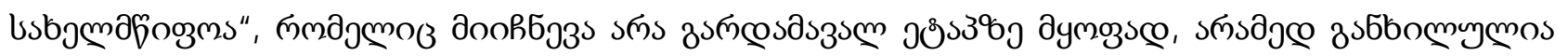

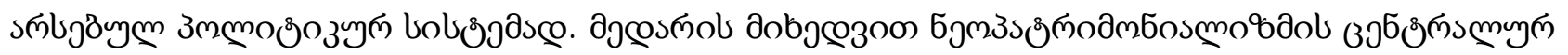

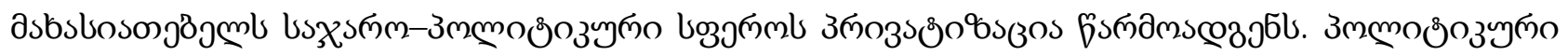

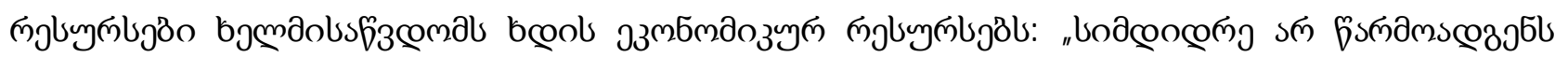

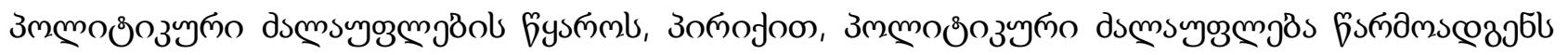

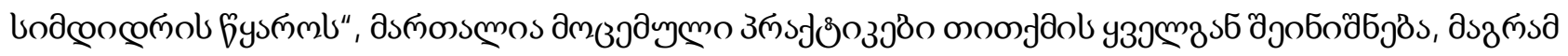

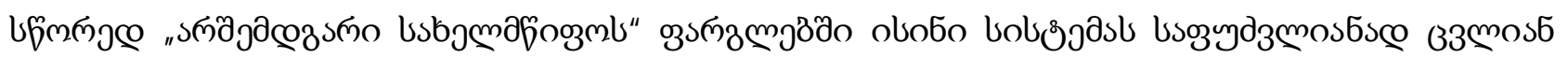
(M edard 1982).

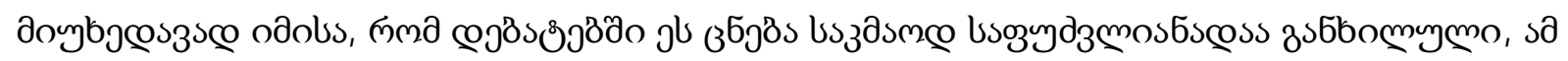

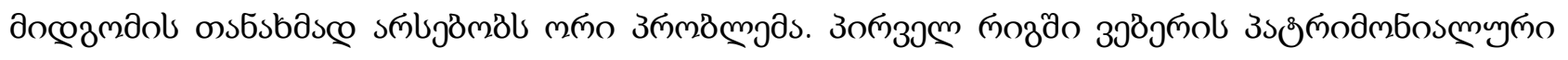

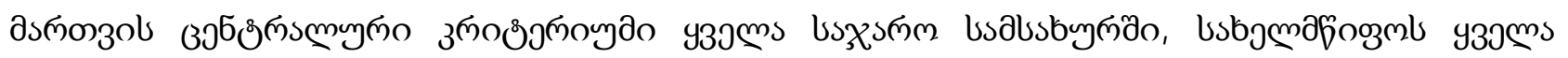

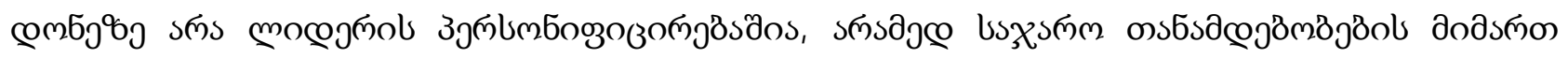

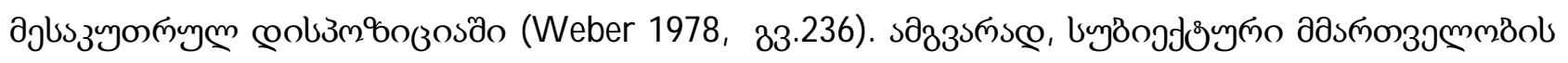

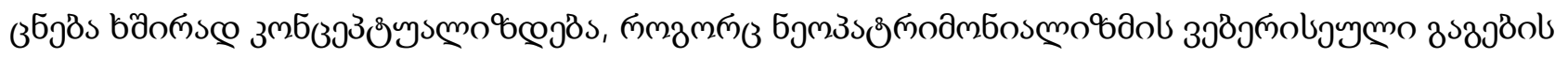

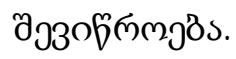

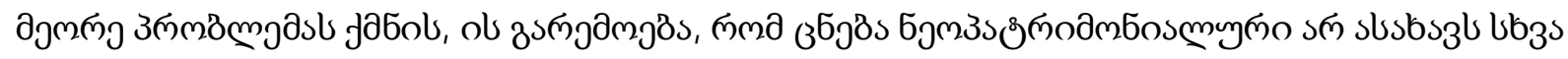

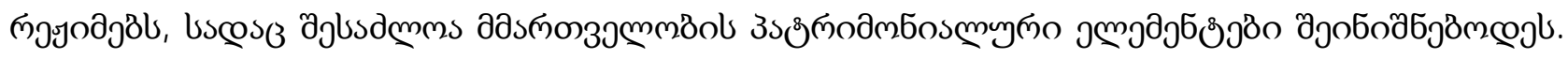

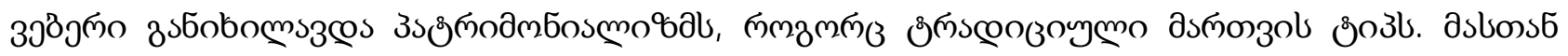

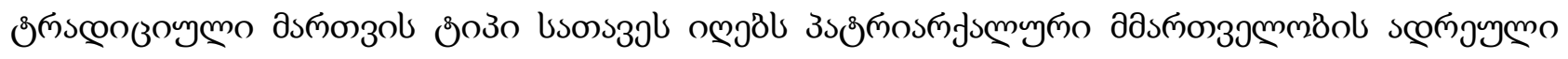

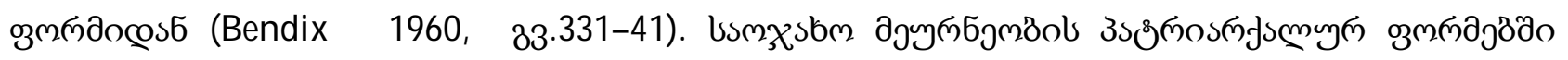

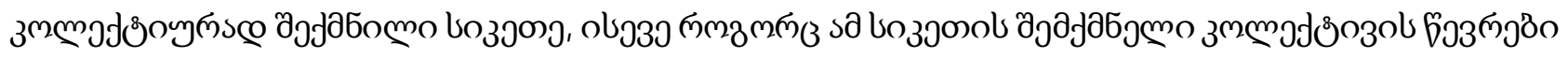

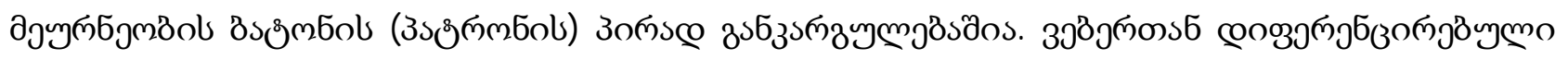

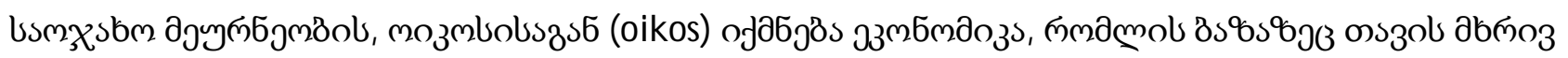

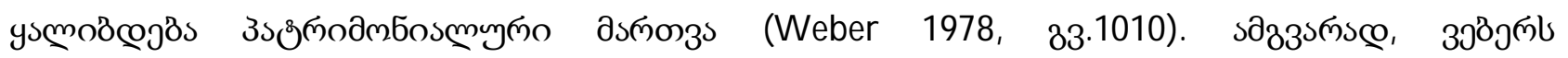

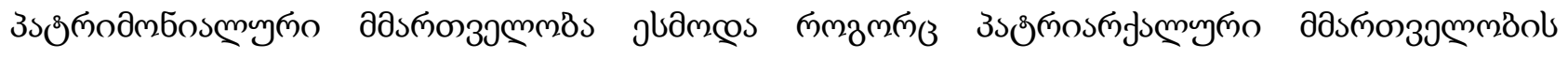

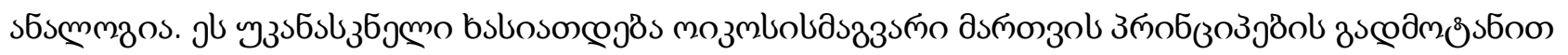

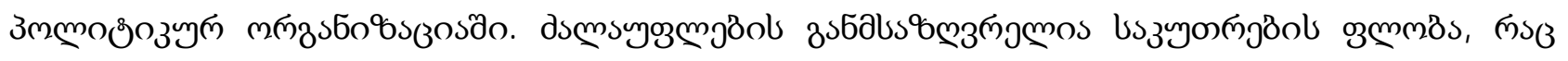

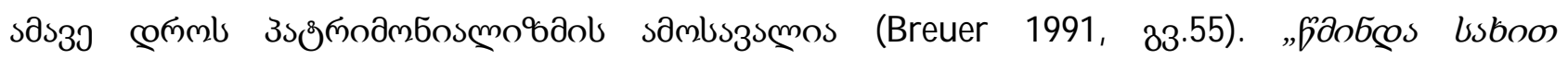

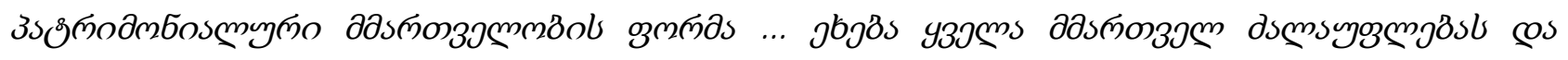

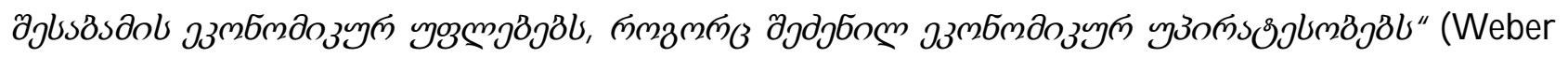

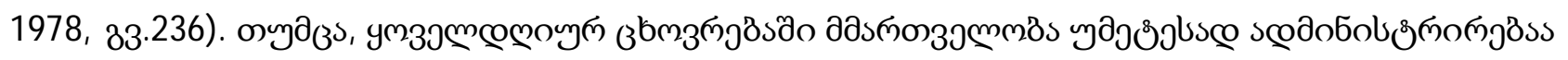
(W eber 1978, 33.220; Poggi 2006, 33.100).

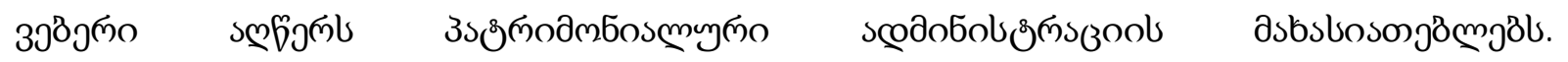

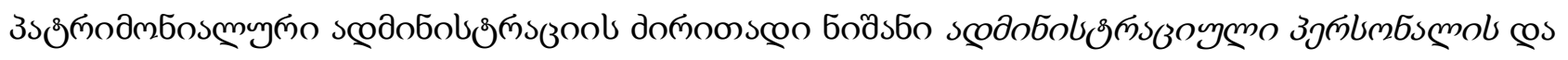

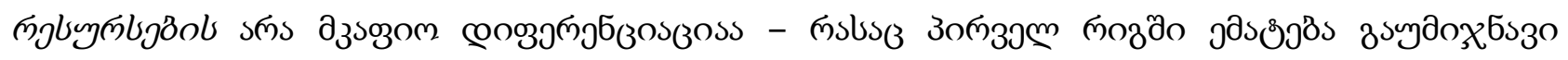

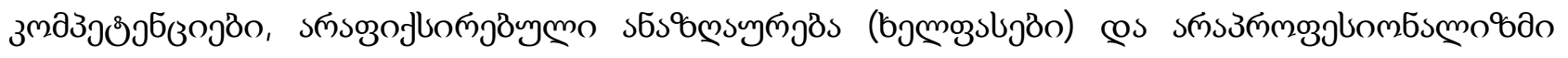
(W eber 1978, 33.228-41, 1025-69). 


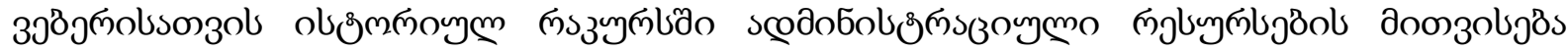

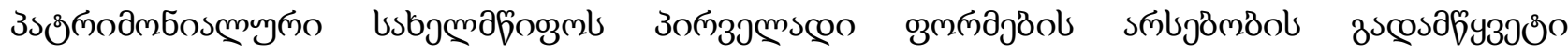

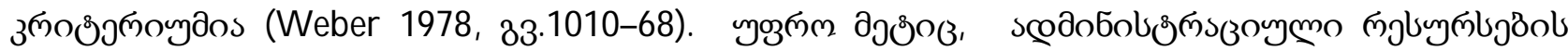

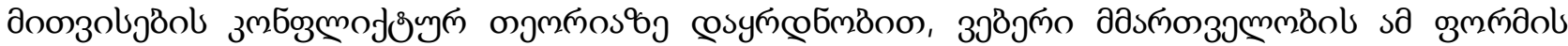

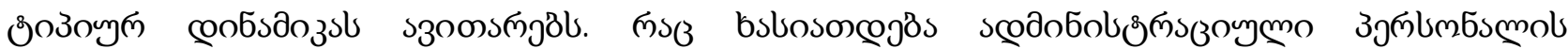

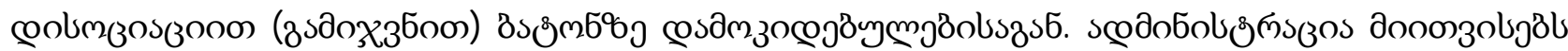

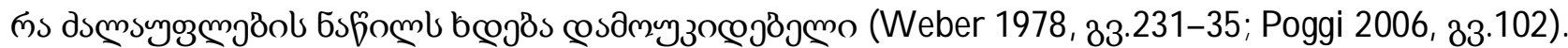

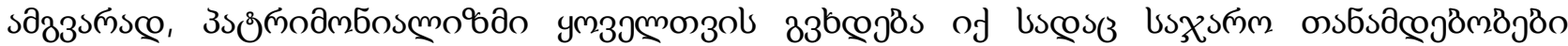

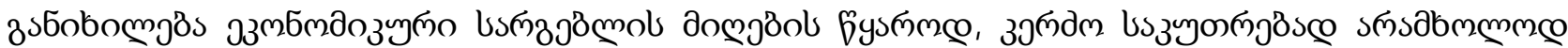

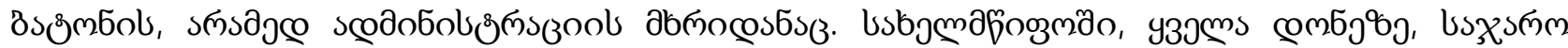

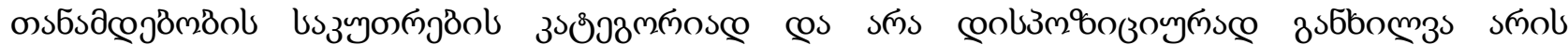

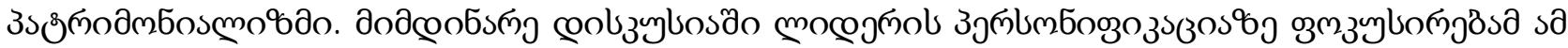

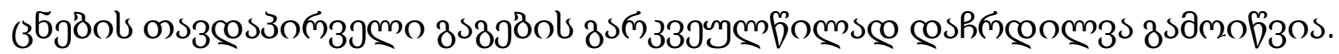

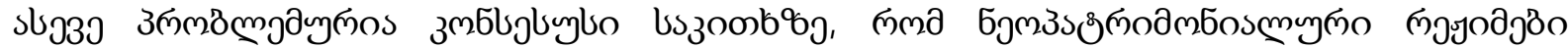

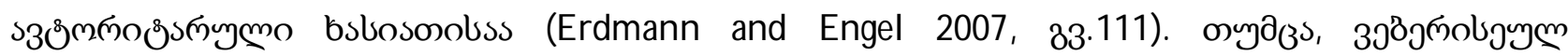

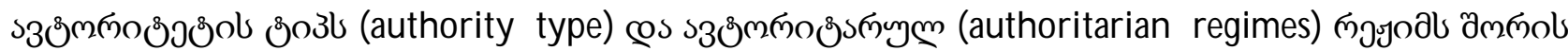

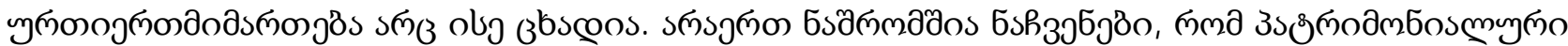

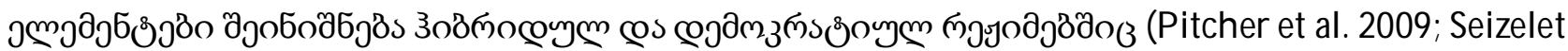

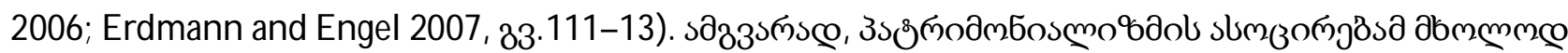

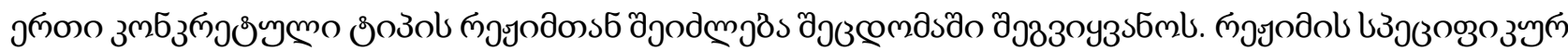

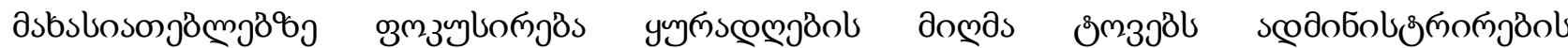

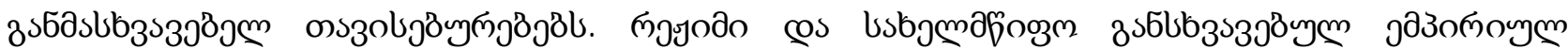

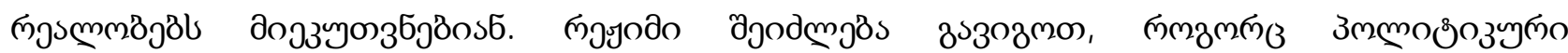

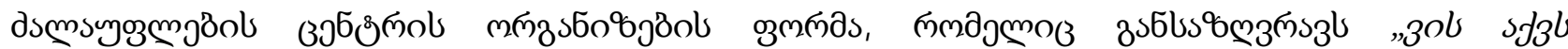

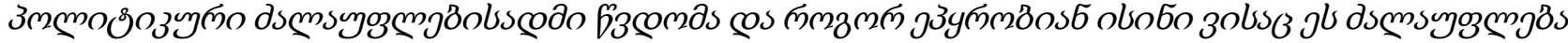

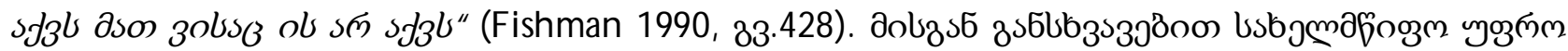

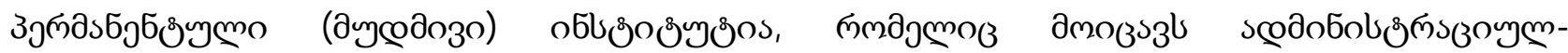

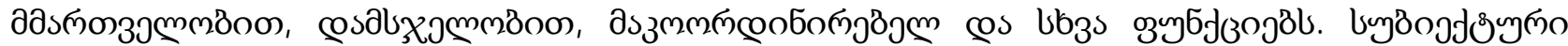

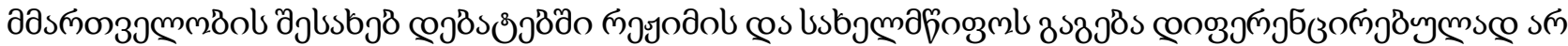

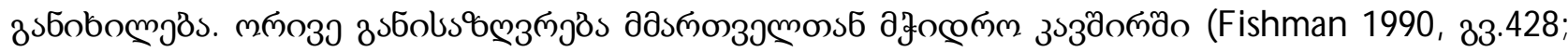
Chehabi and Linz 1998b, 33.10-13).

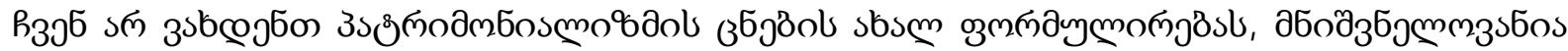

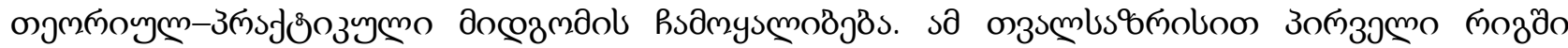

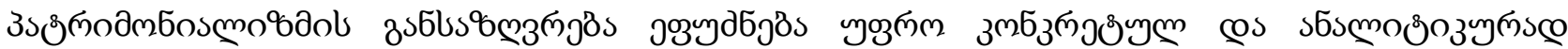

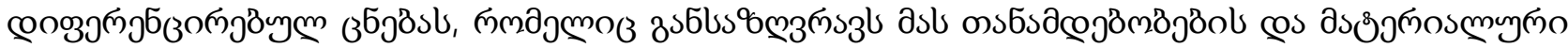

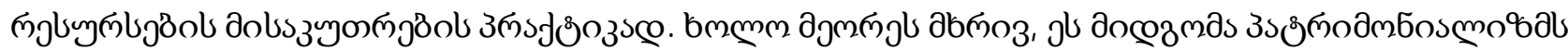

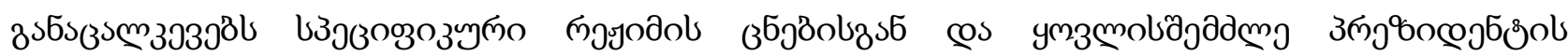

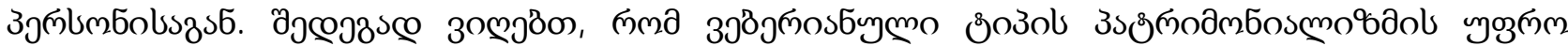

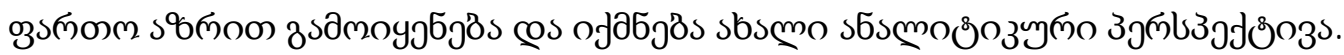




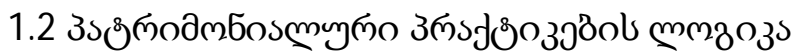

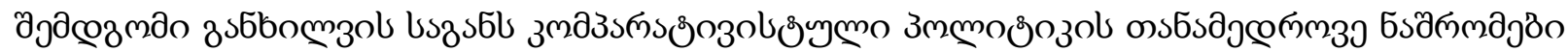

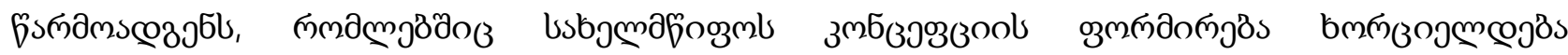

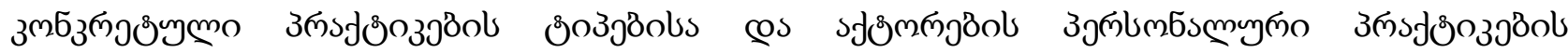

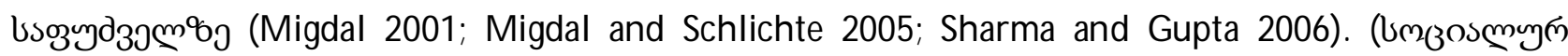

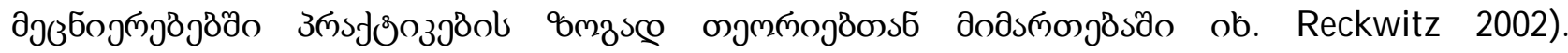

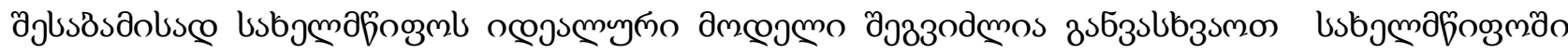

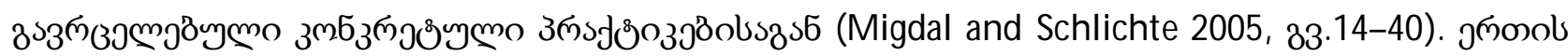

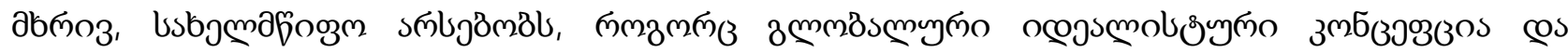

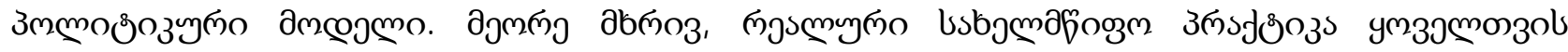

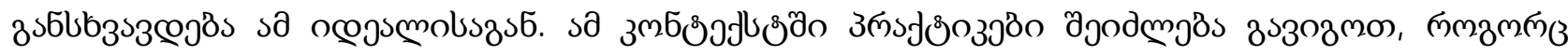

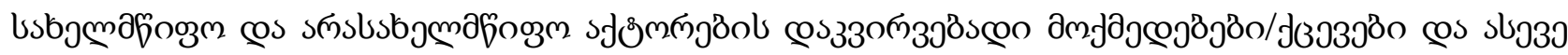

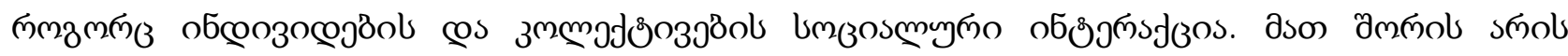

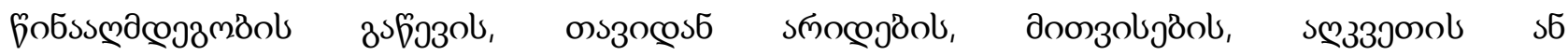

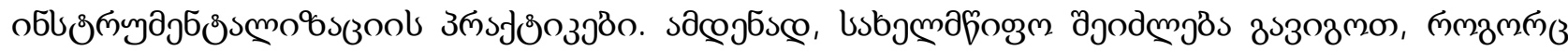

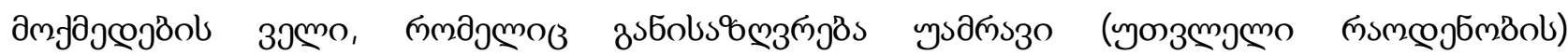

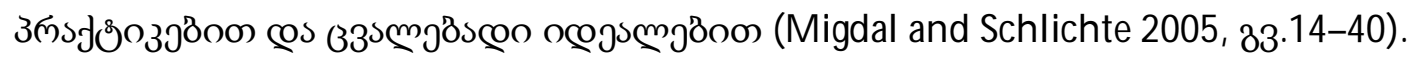

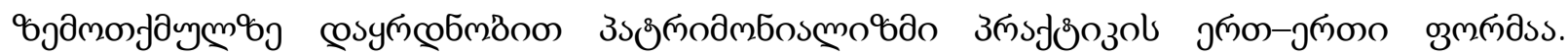

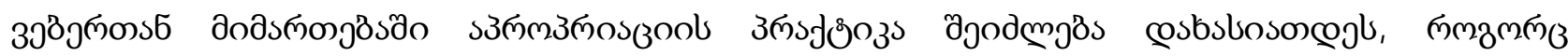

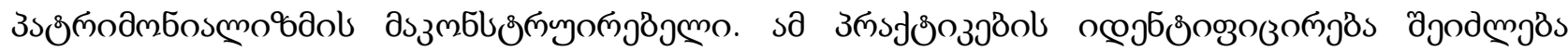

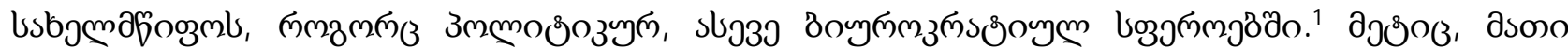

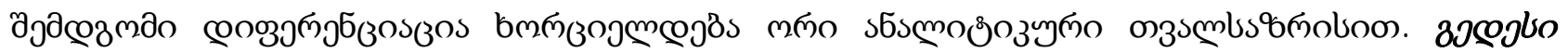

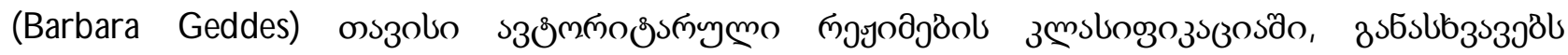

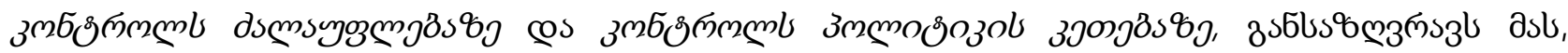

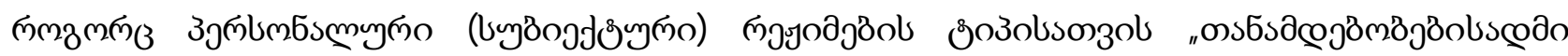

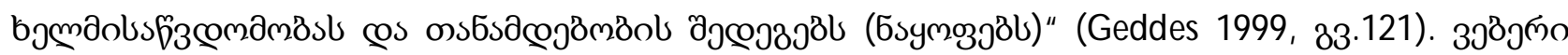

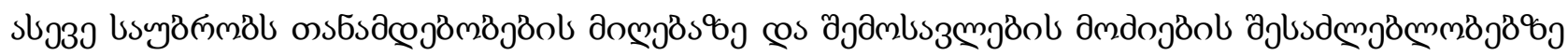

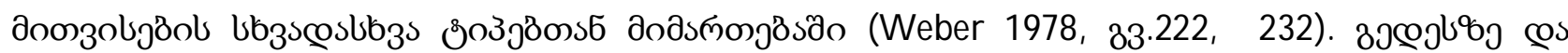

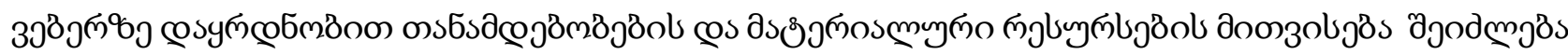

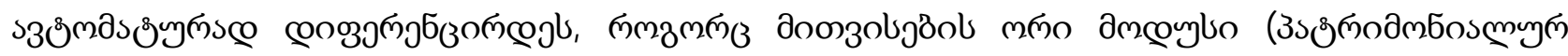
змбఠీ

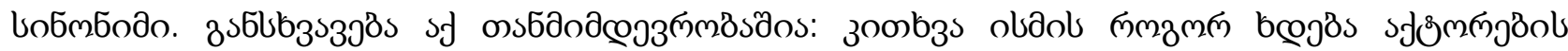

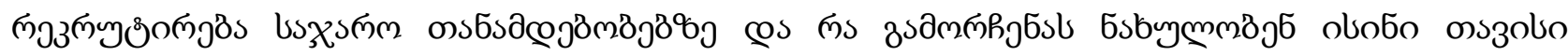

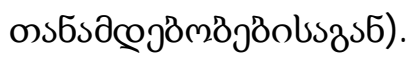

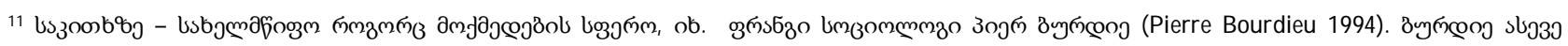

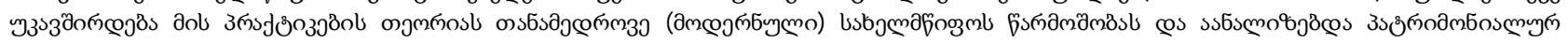

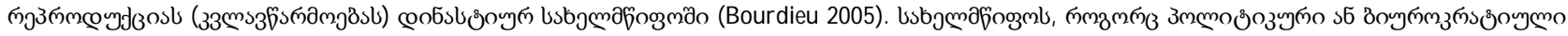

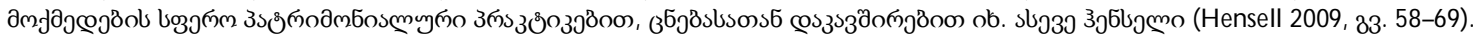




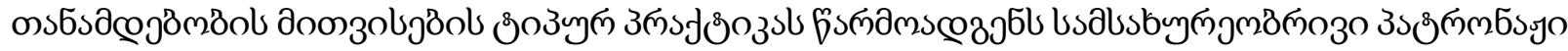

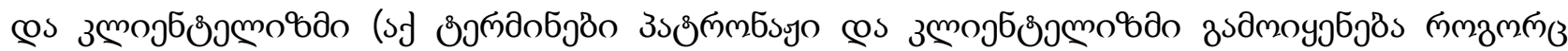

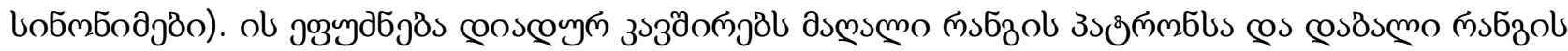

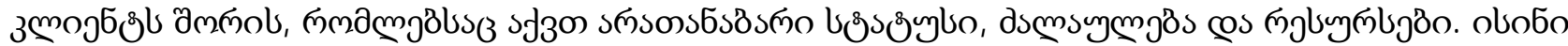

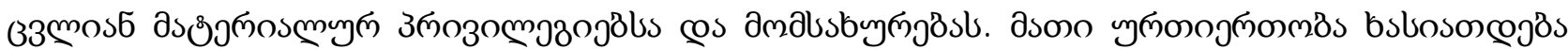

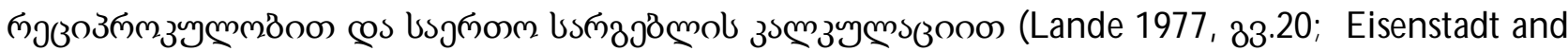

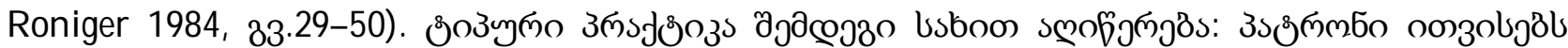

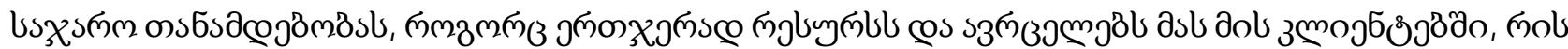

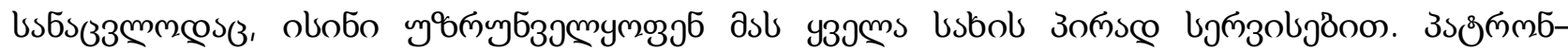

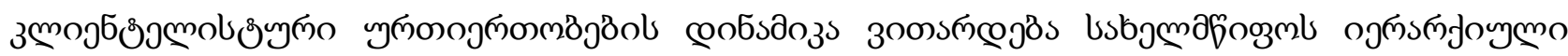

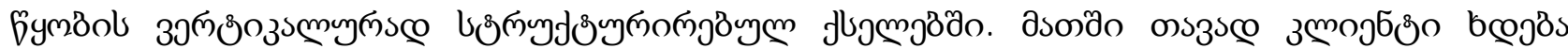

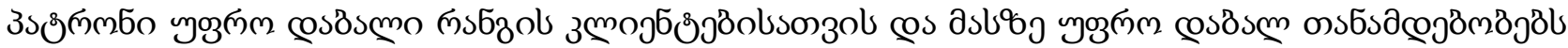

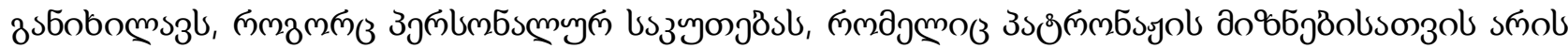

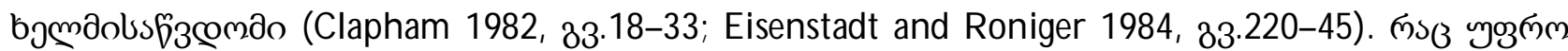

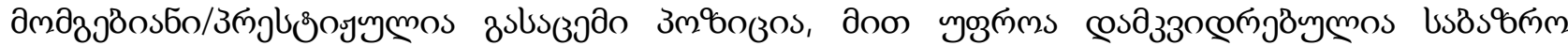

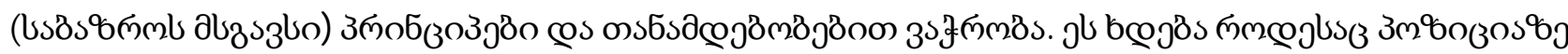

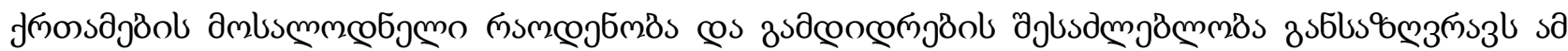

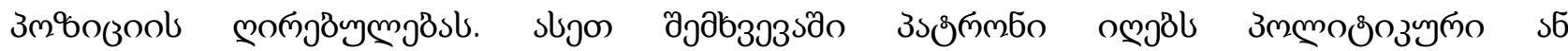

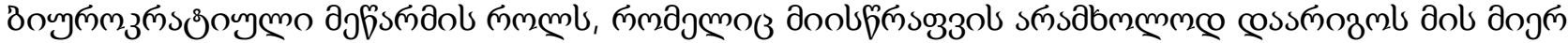

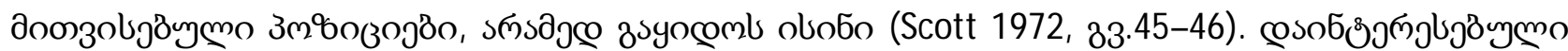

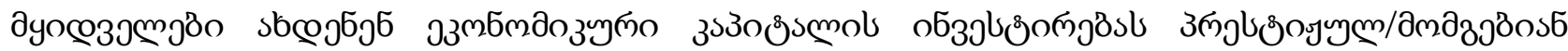

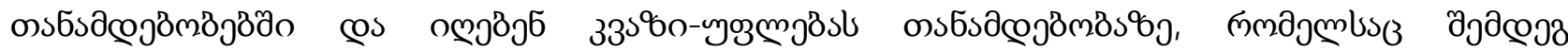

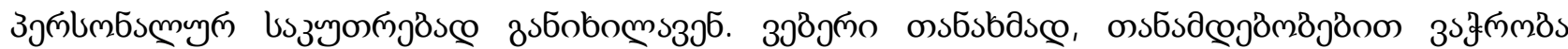

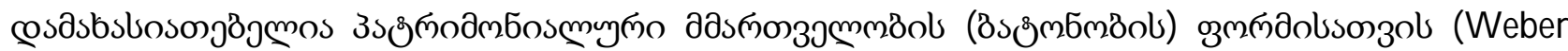

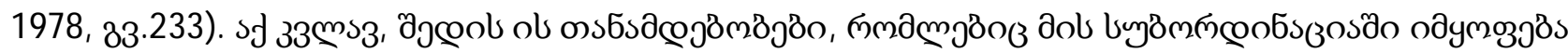

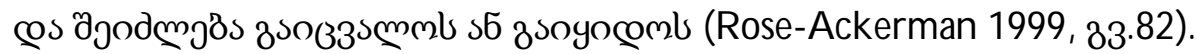

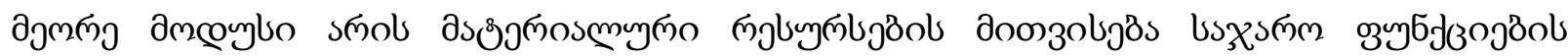

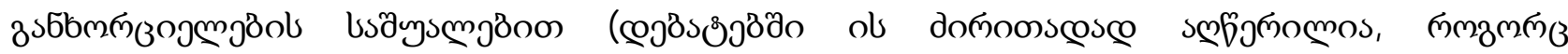

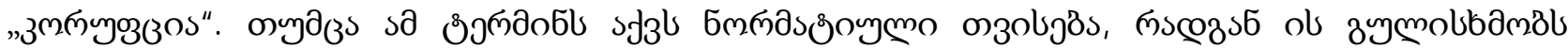

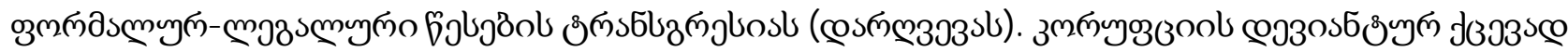

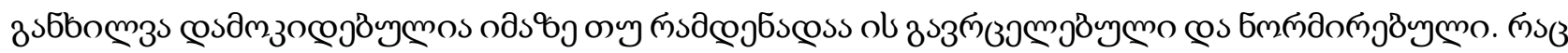

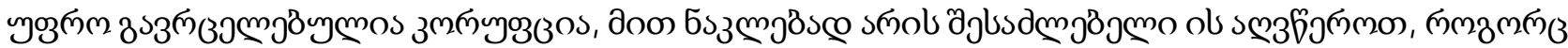

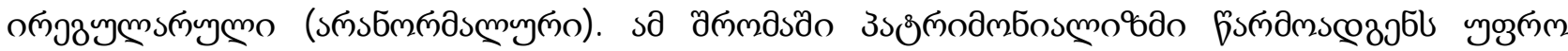

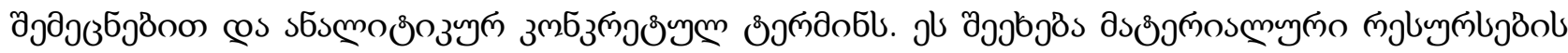

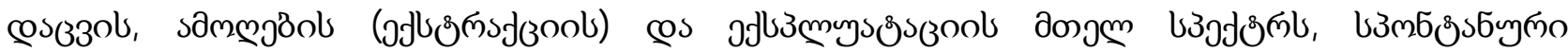

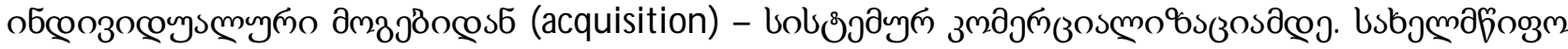

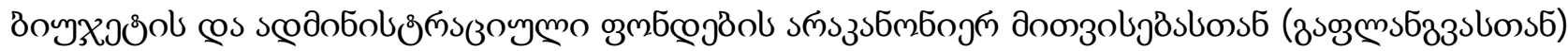

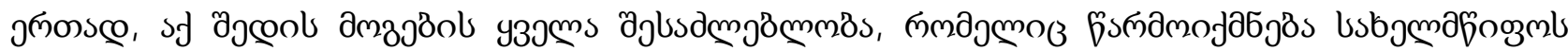

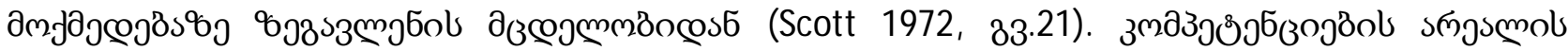

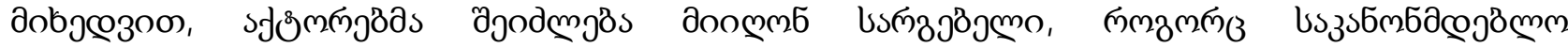




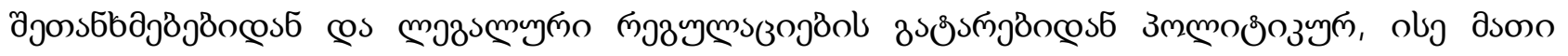

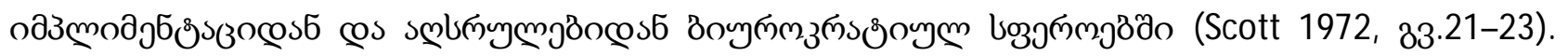

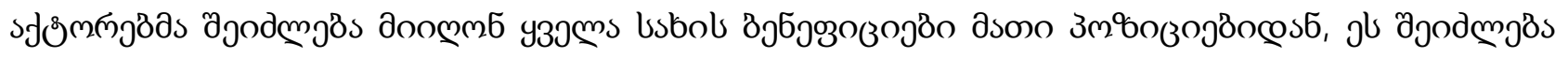

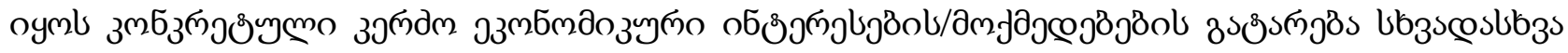

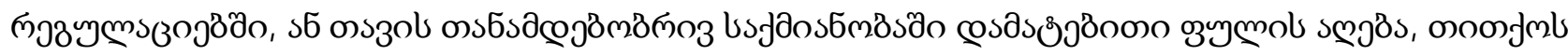

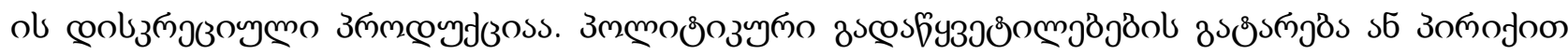

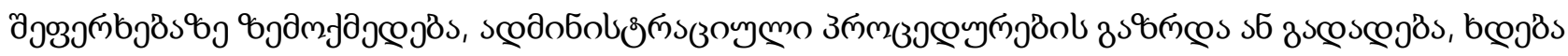

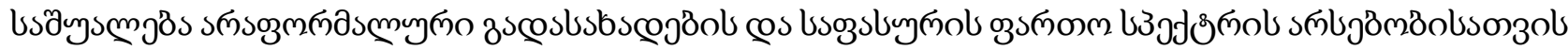

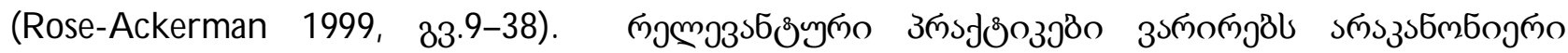

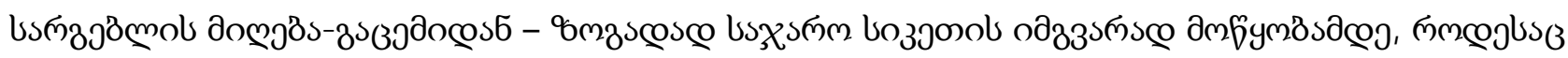

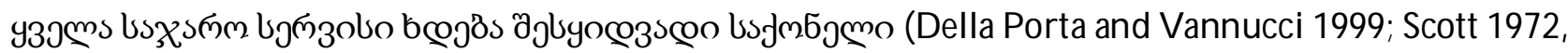
33.54-91; Rose-Ackerman 1999, 33.9-38, 91-126).

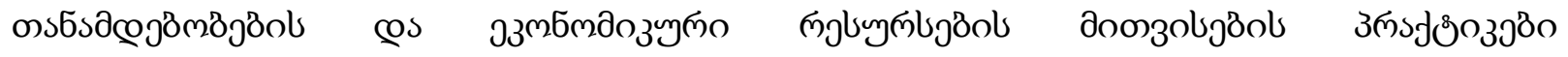

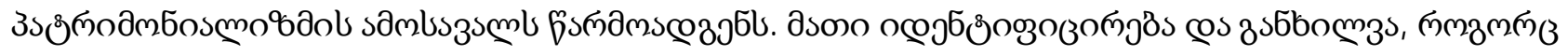

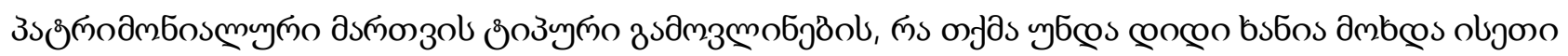

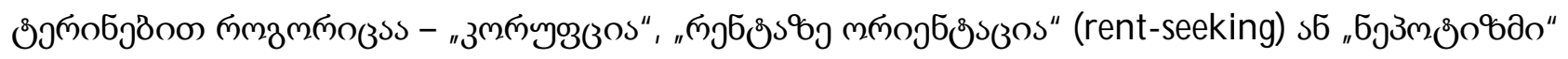
(Eisenstadt 1973; Rudolph and Rudolph 1979; Clapham 1985, 83.48-60; Bratton and van de W alle

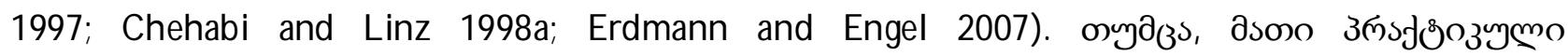

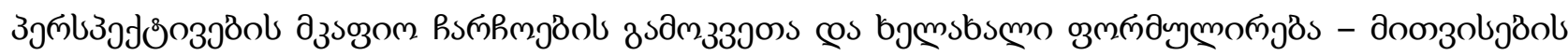

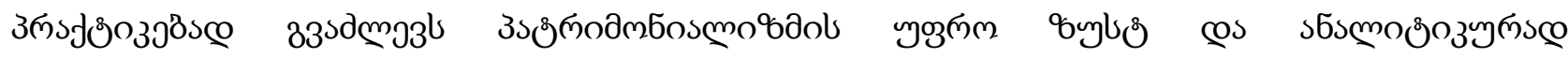

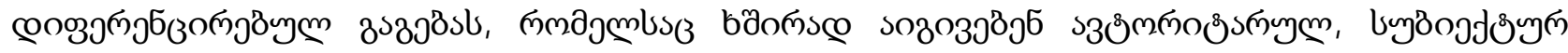

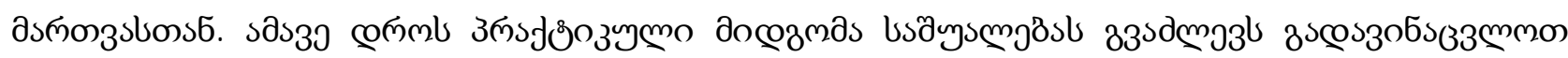

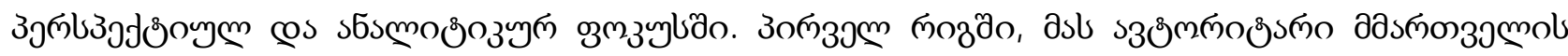

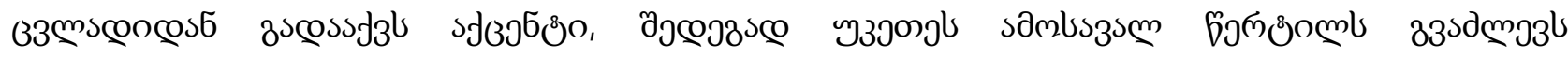

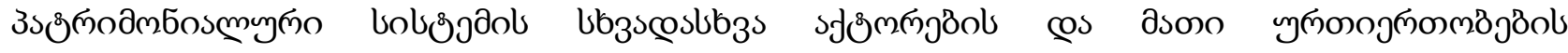

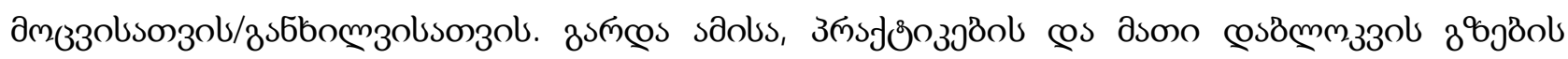

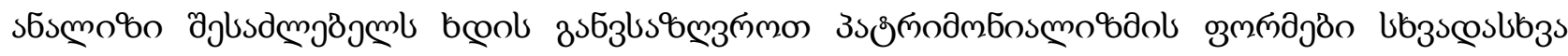

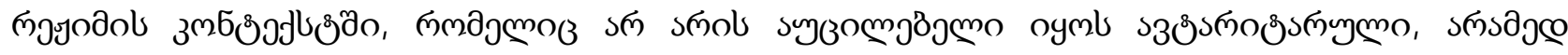

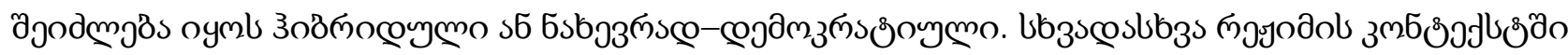

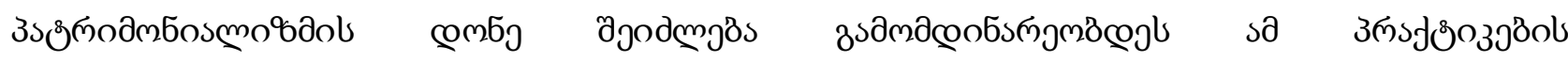

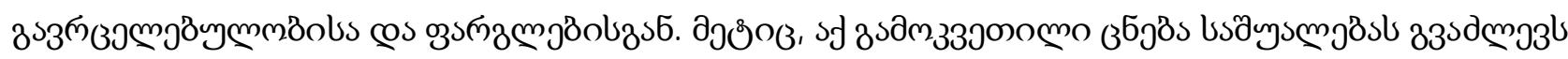

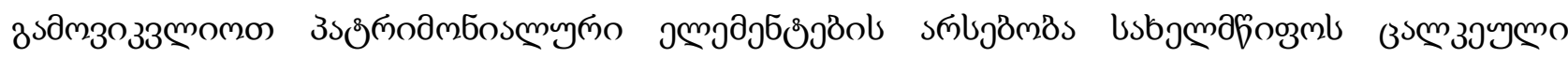

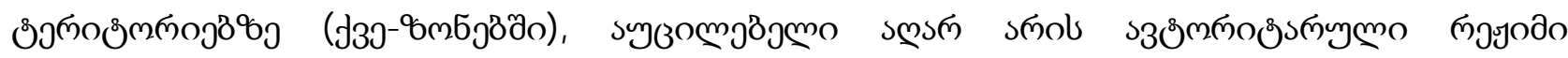

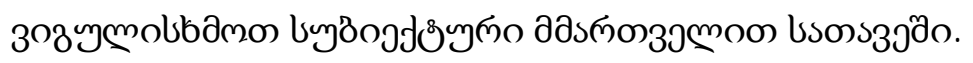

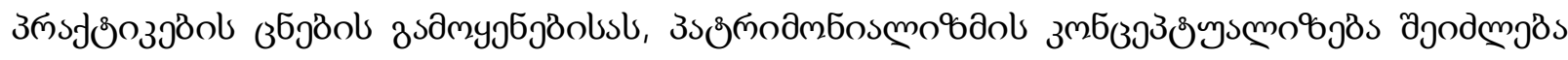

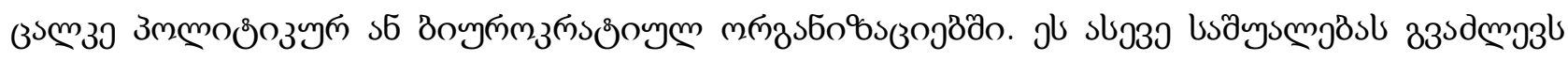

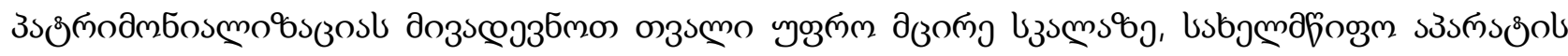

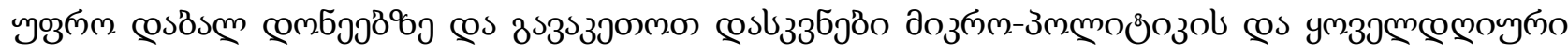

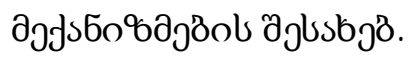




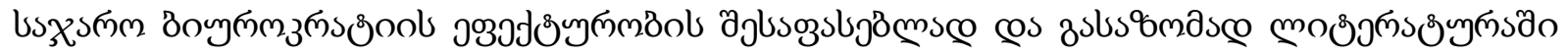

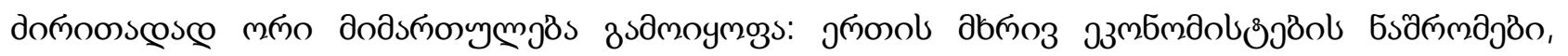

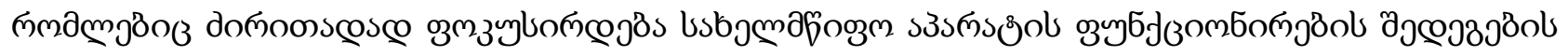

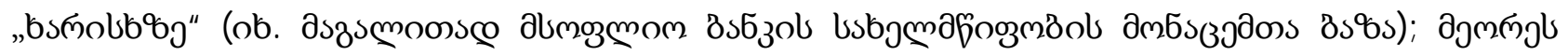

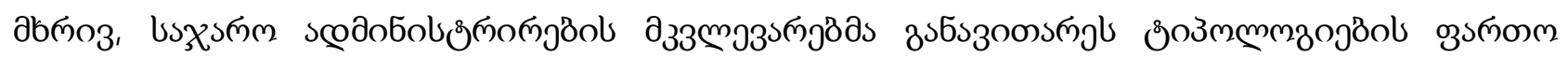

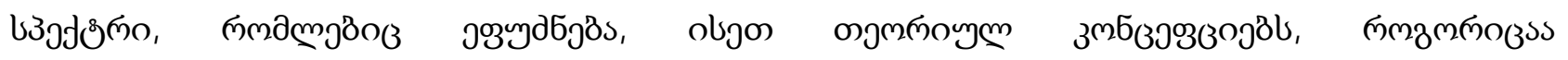

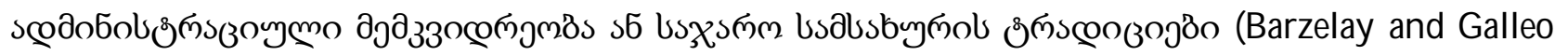
2010; Painter and Peters 2010).

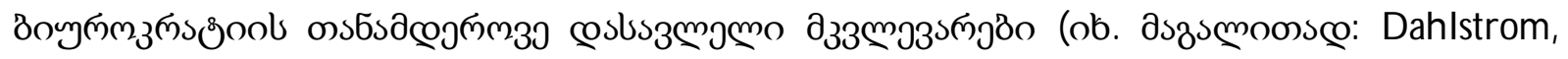

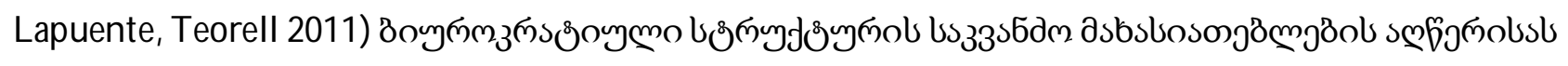

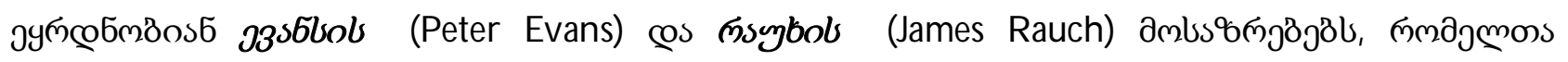

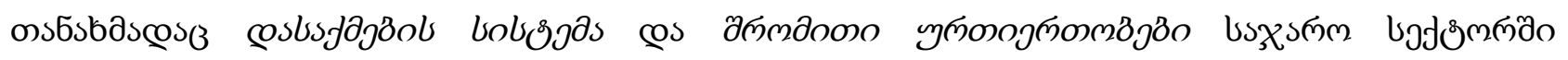

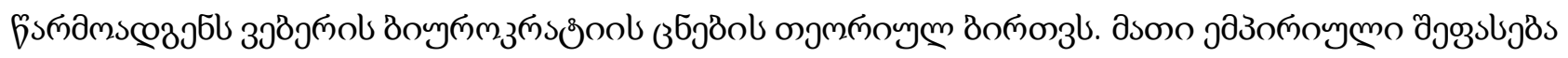

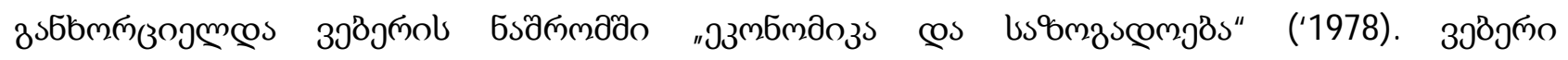

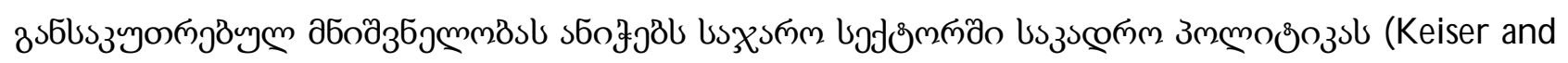

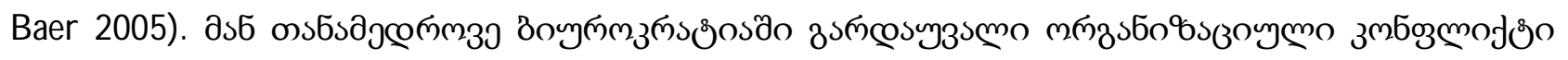

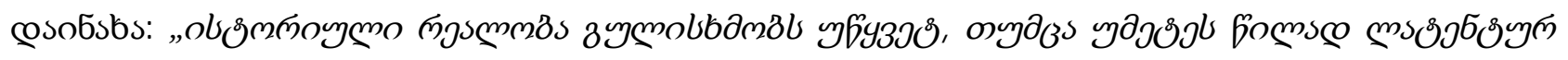

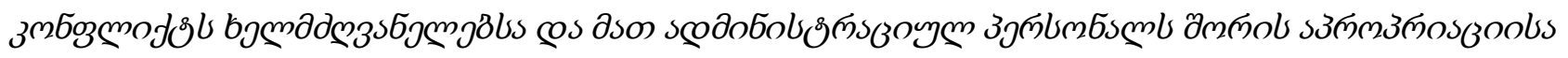

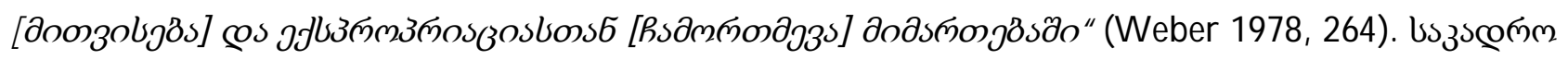

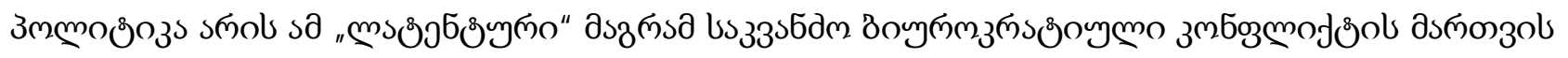

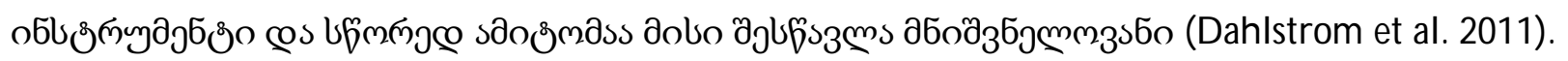

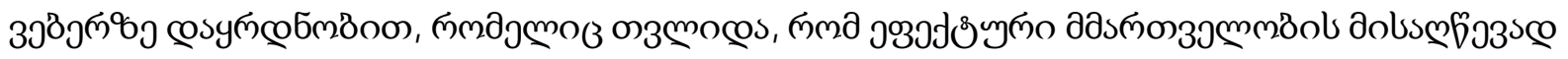

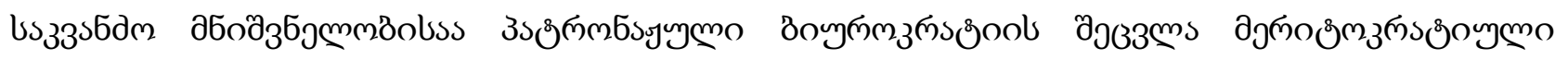

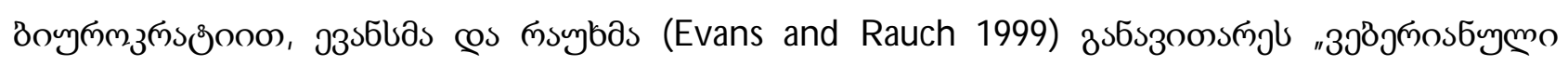

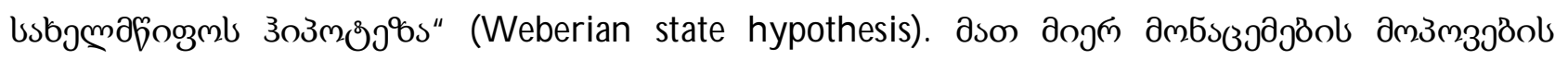

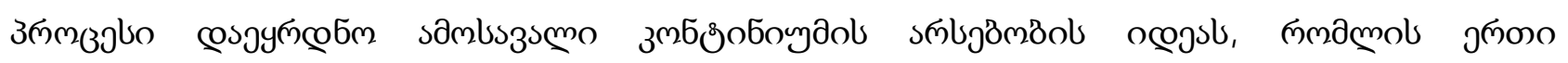

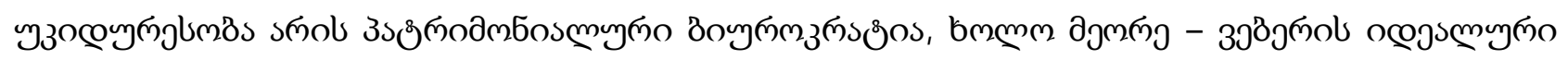

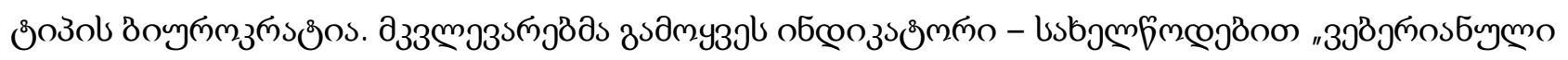

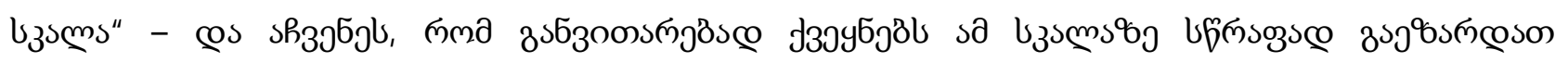

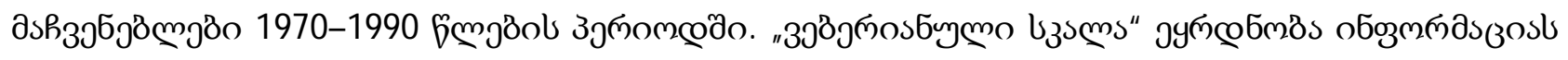

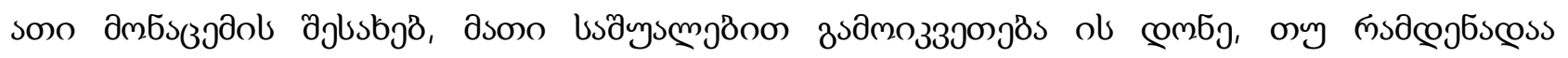

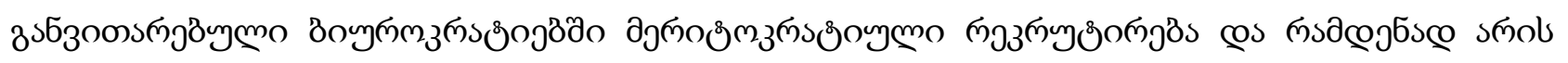

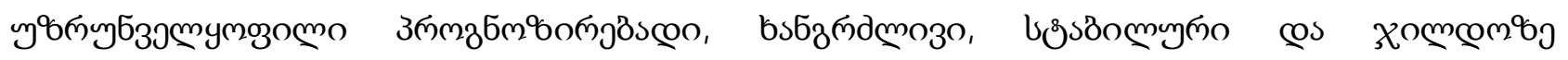

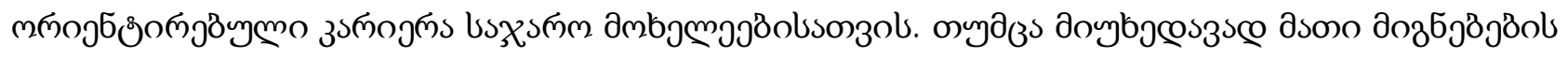

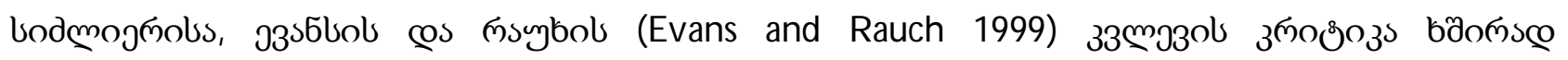

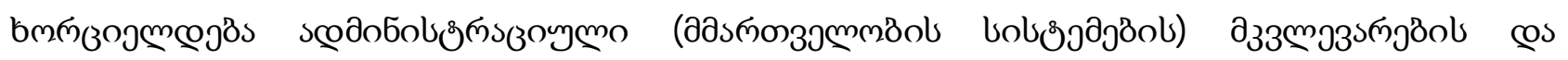

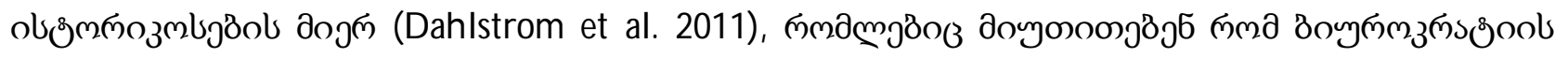

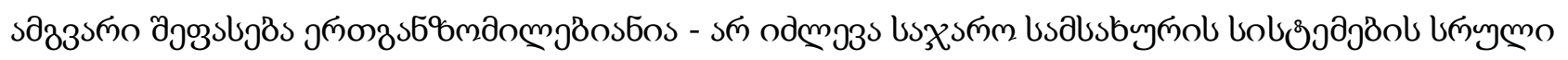

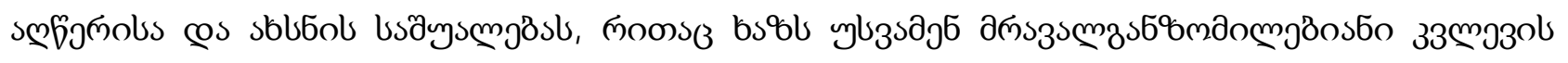




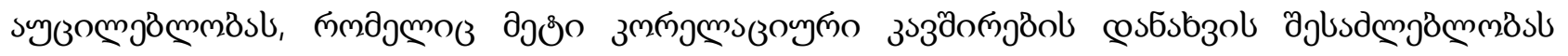

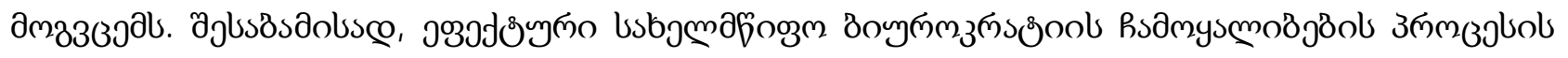

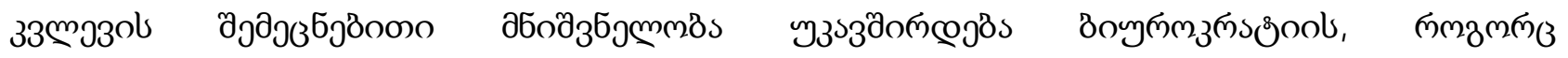

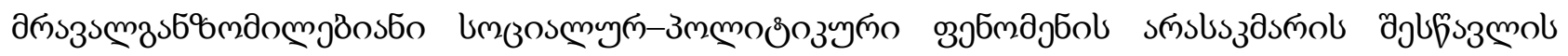

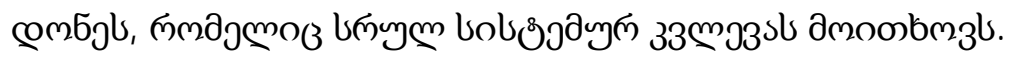

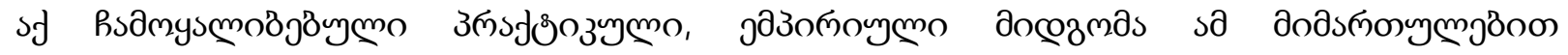

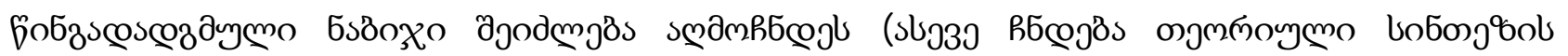

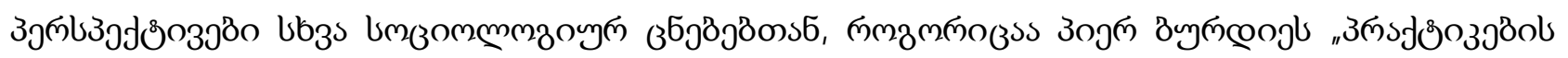
оэм๓о (H ensell 2009, 33.49-70)).

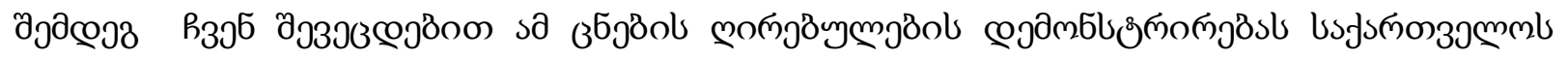

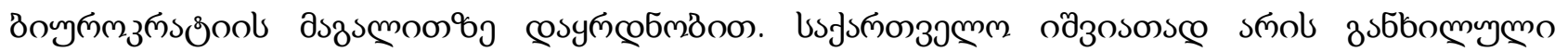

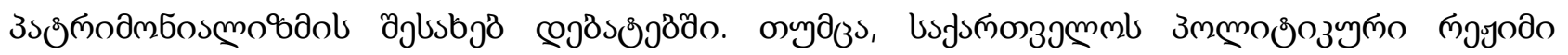

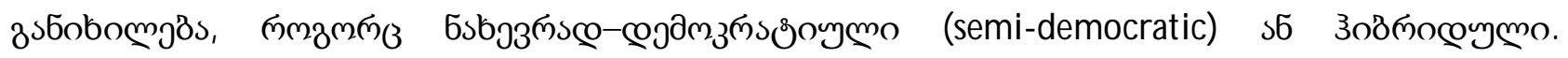

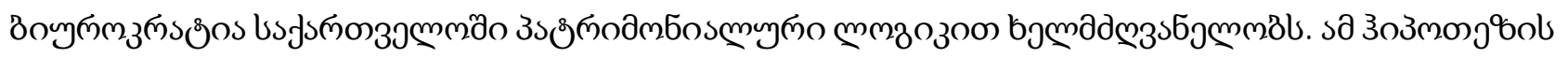

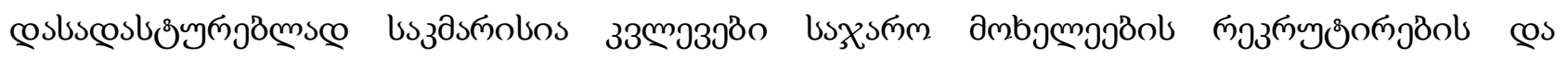

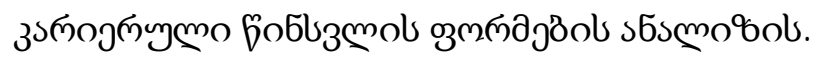

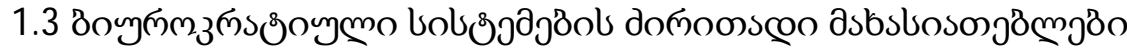

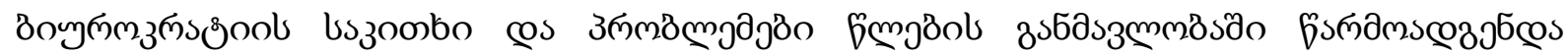

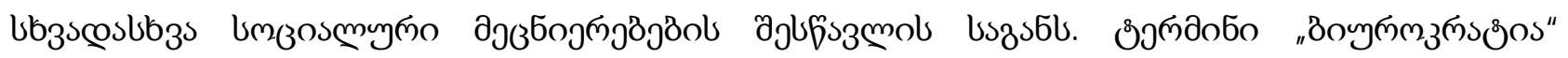

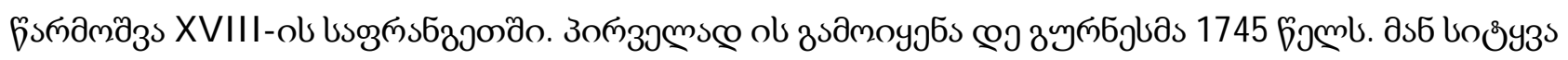

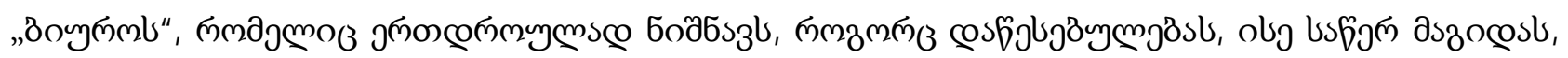

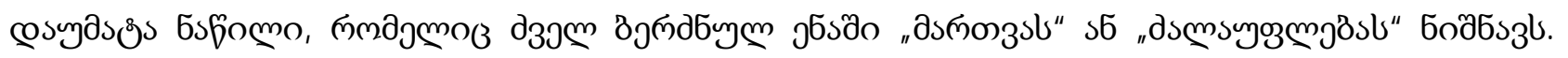

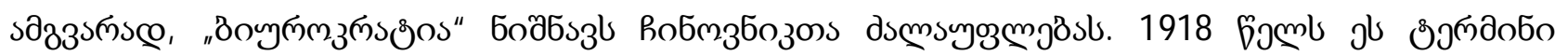

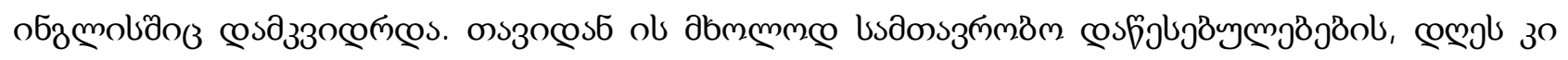

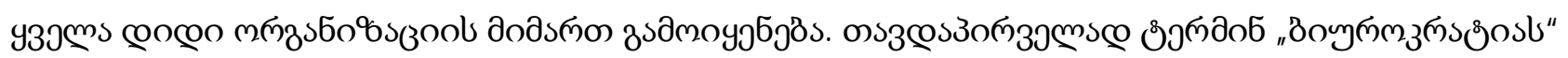

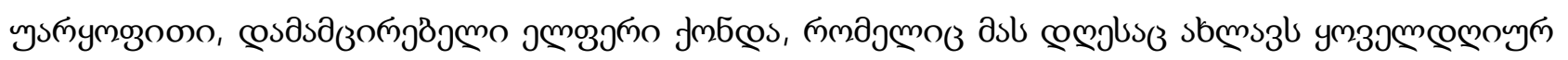

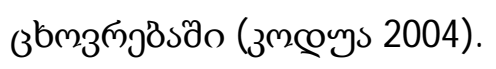

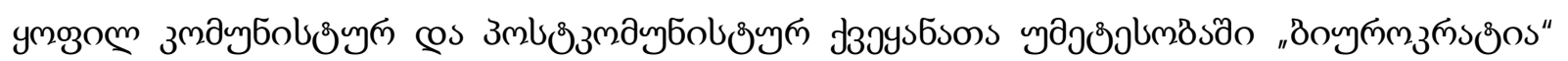

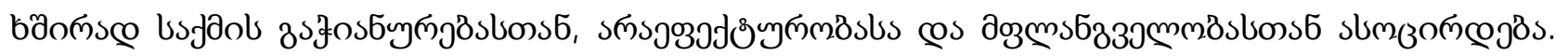

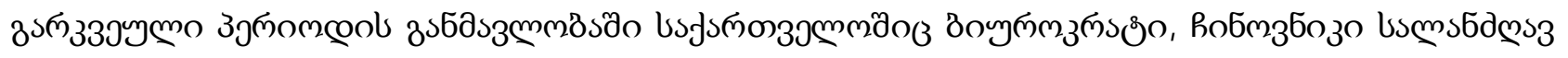

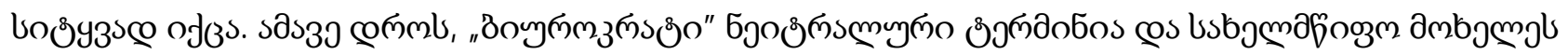

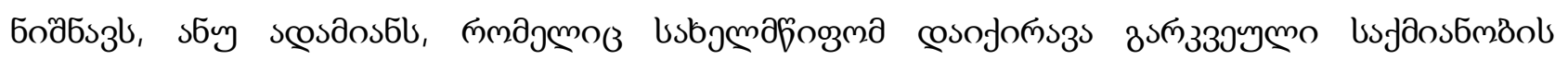

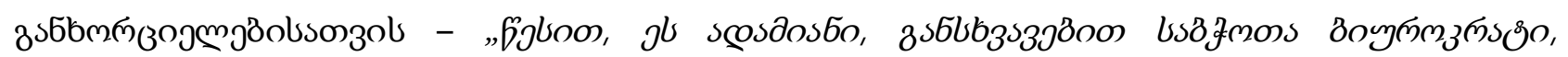

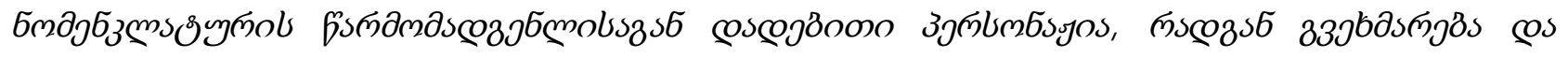

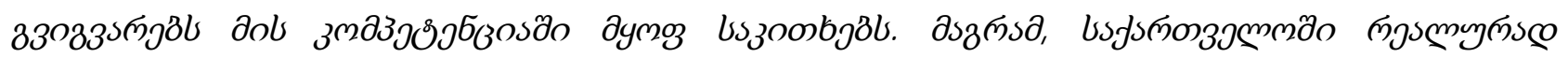




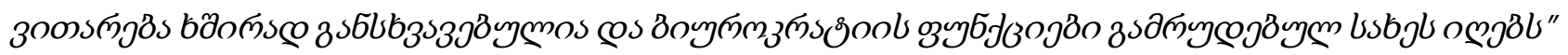

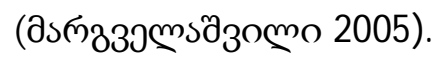

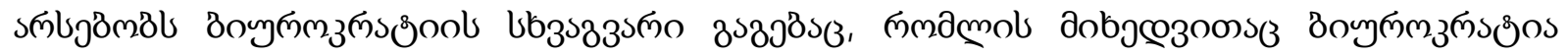

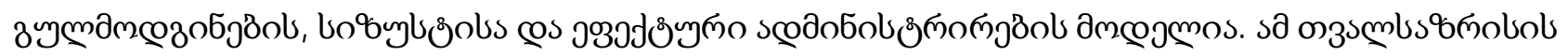

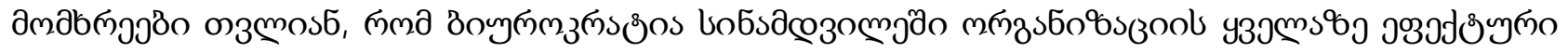

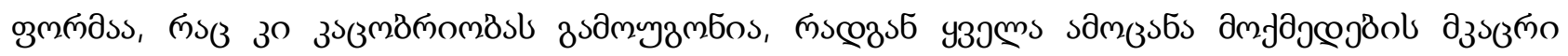

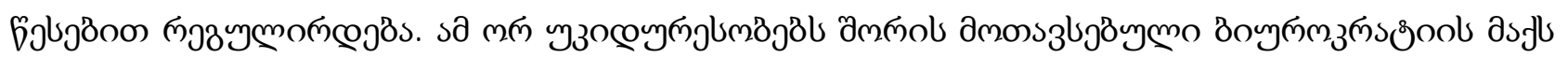

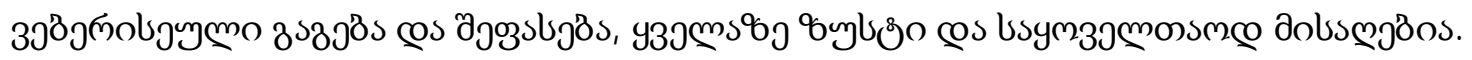

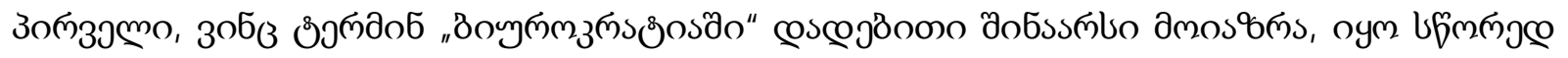

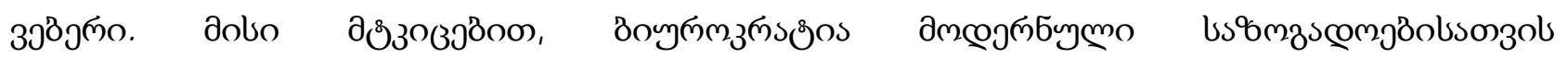

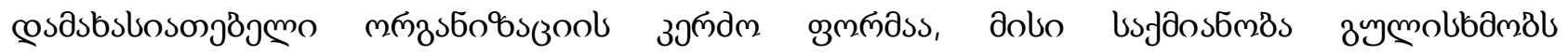

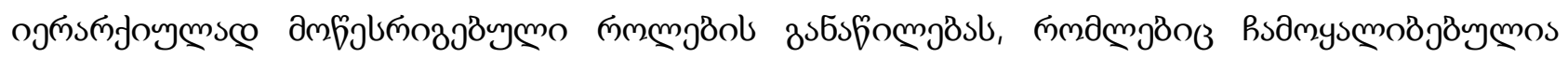

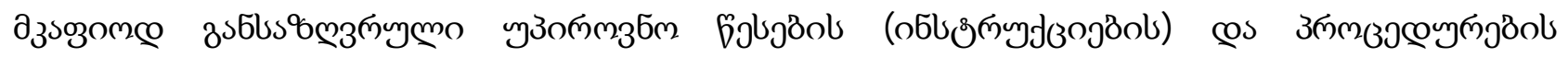

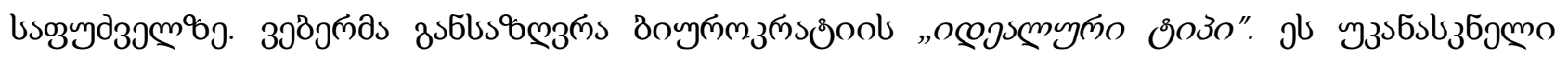

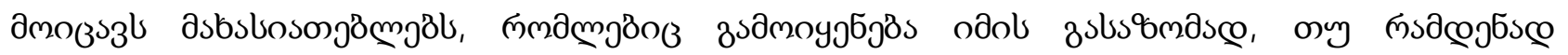

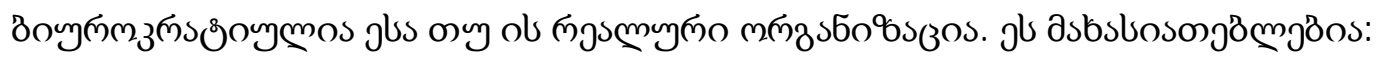

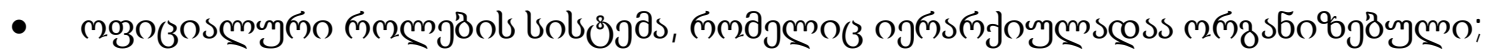

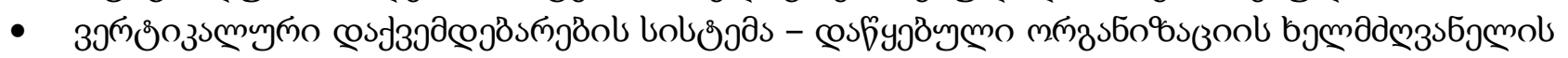
эубб

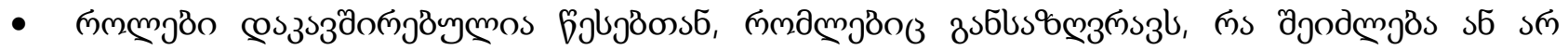

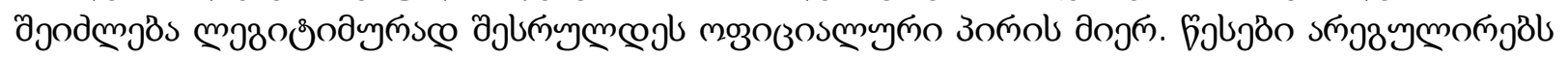

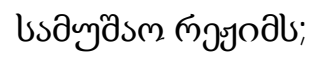

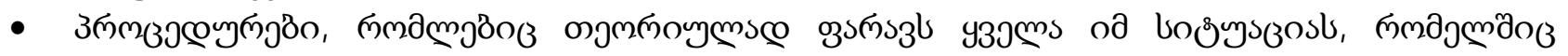

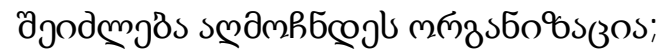

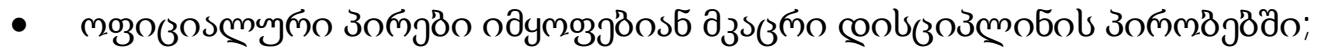

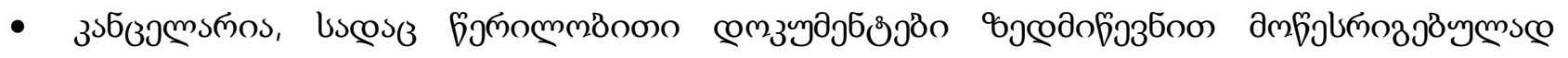
oбsbjas;

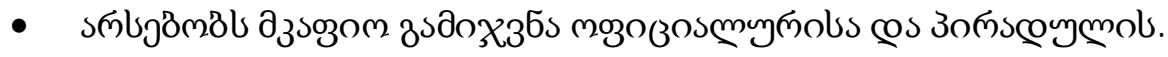

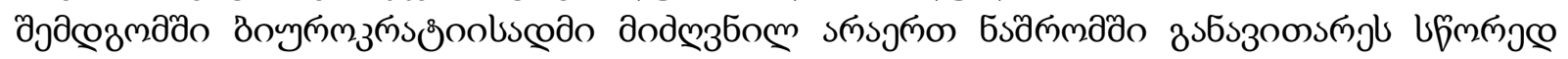

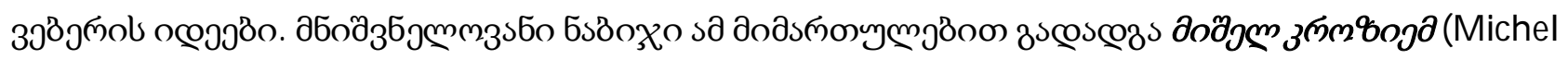

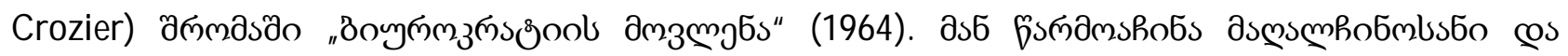

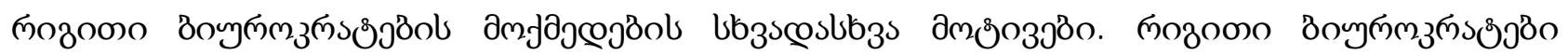

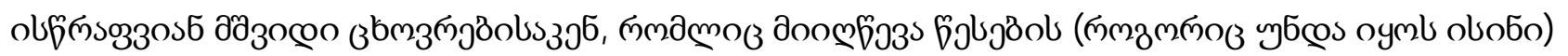

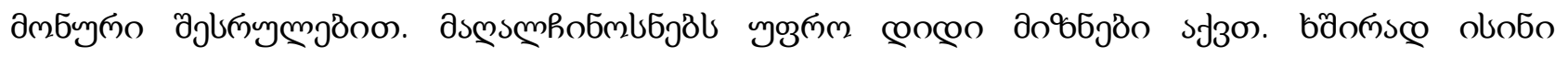

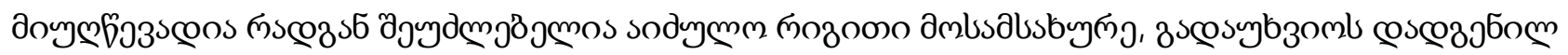

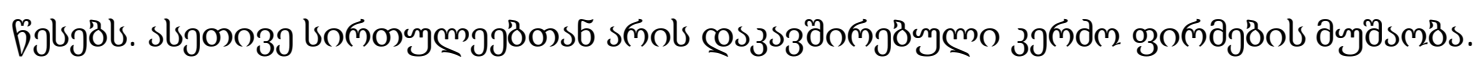

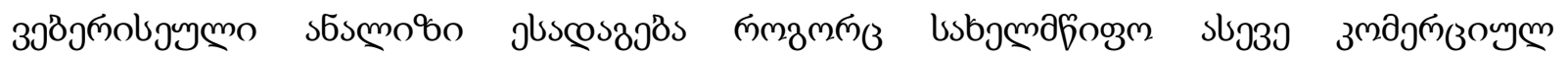

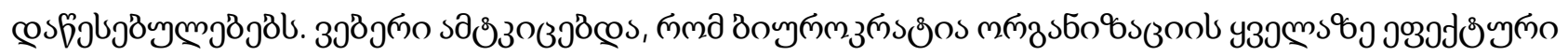

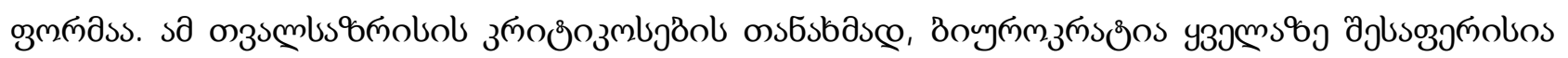

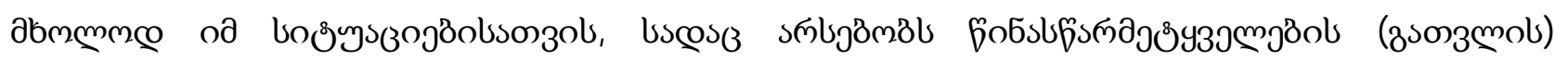




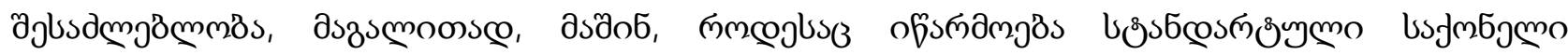

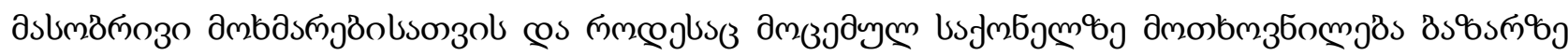

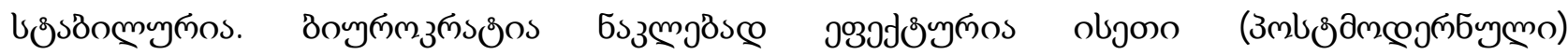

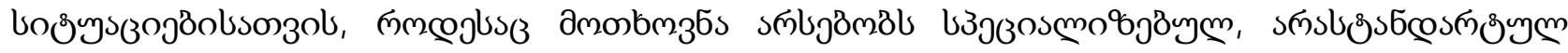
usfmbjm⿺辶.

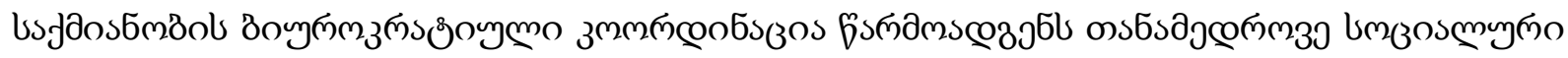

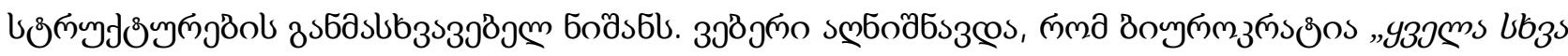

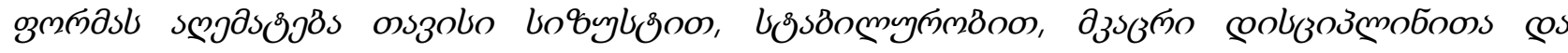

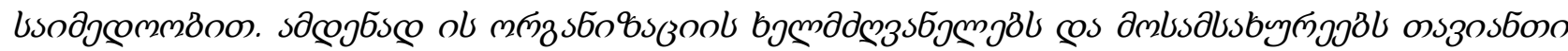

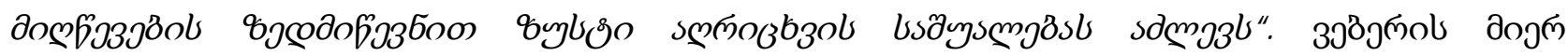

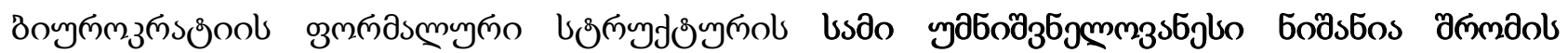

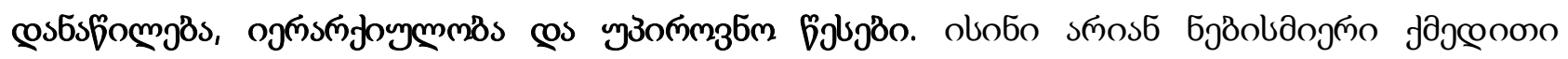

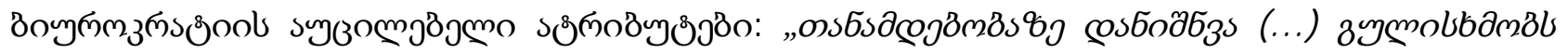

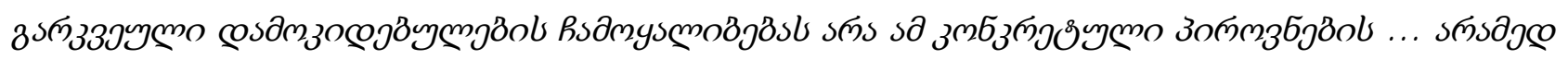

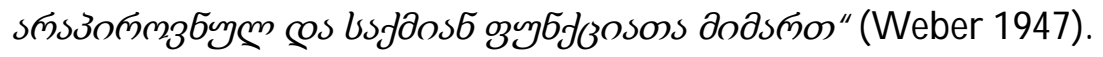

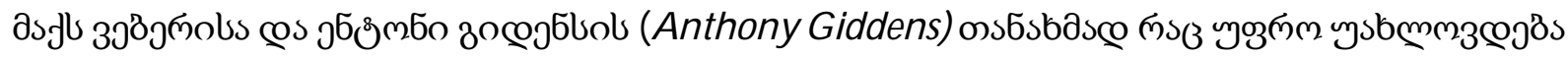

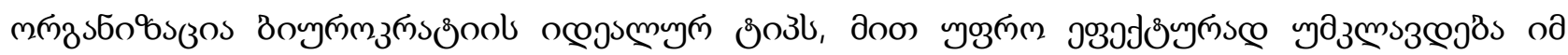

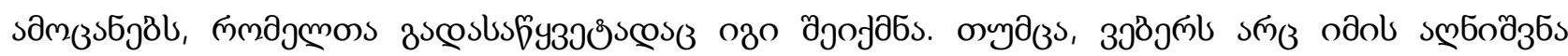

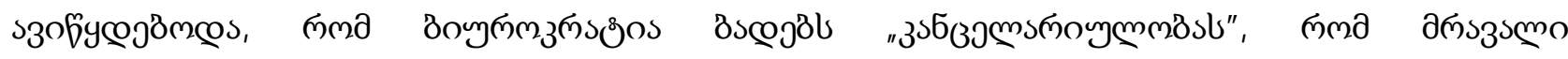

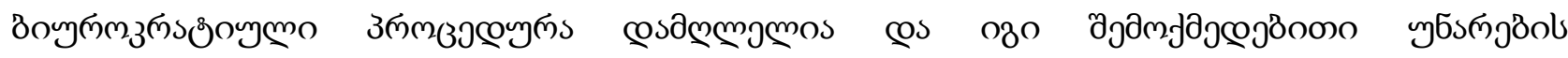

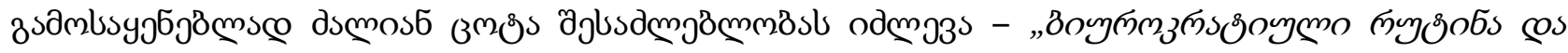

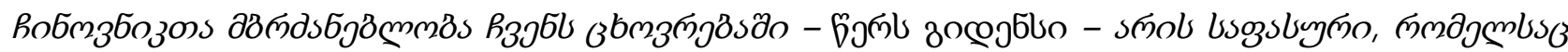

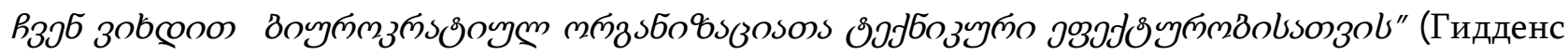
1999, 83.270).

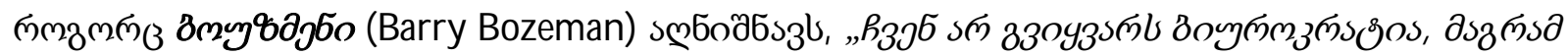

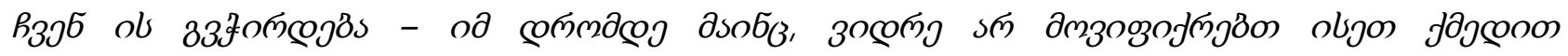

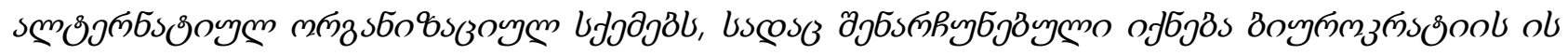

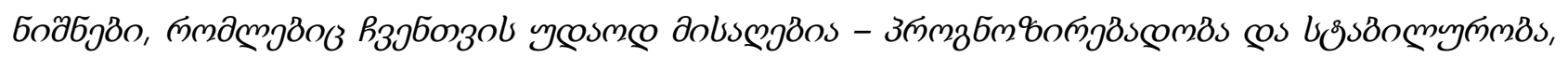

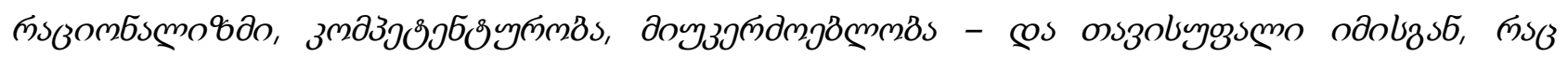

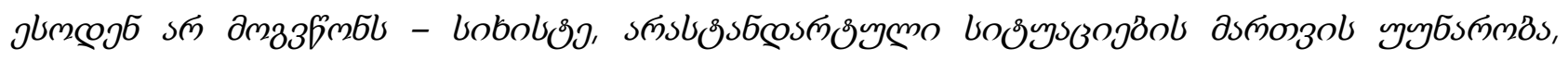

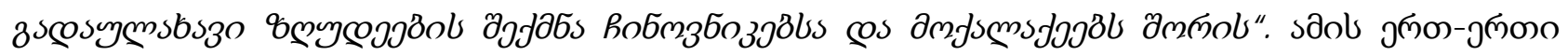

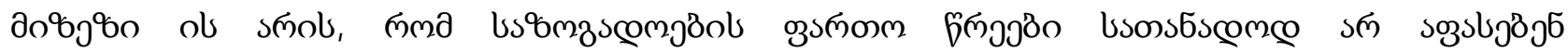

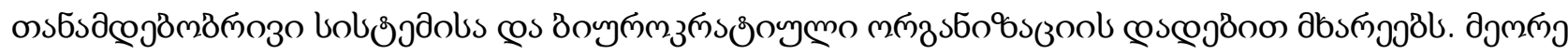

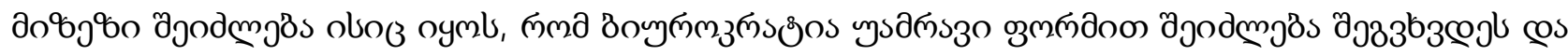

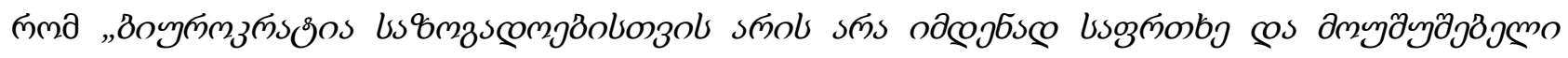

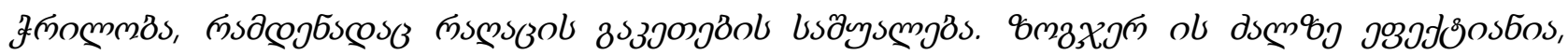

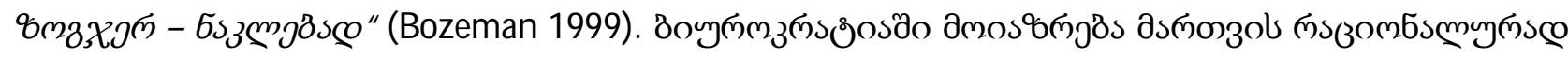

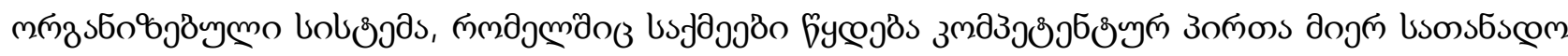

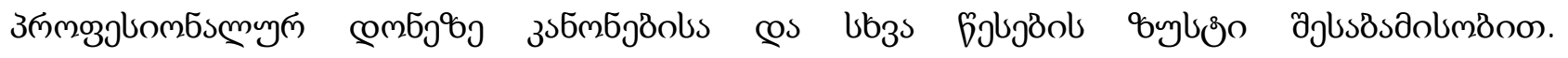




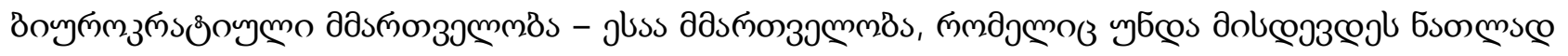

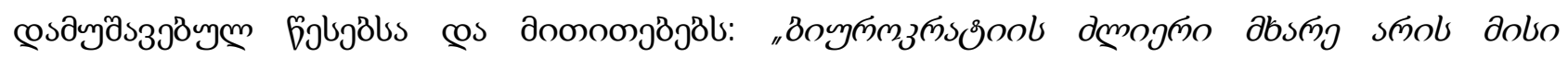

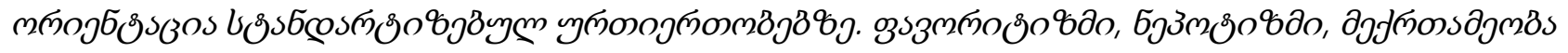

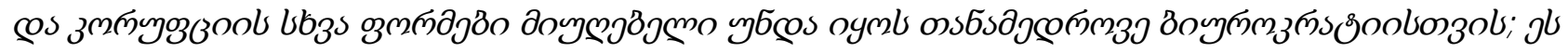

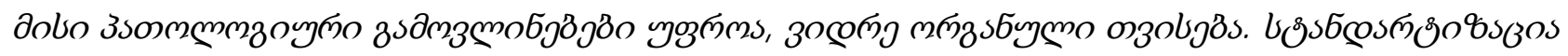

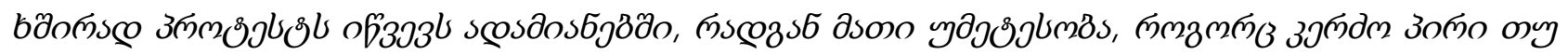

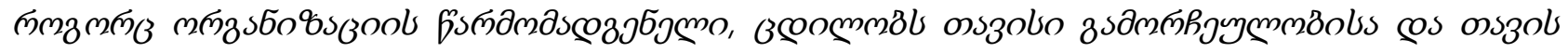

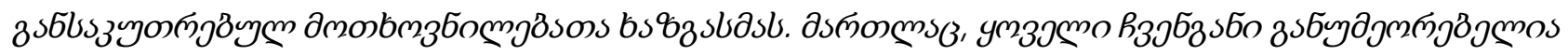

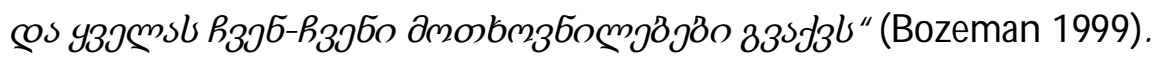

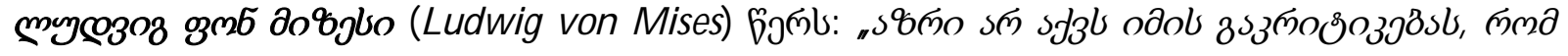

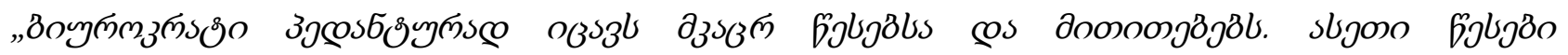

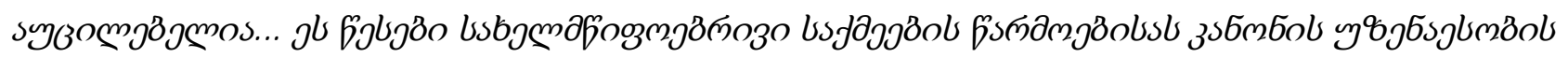

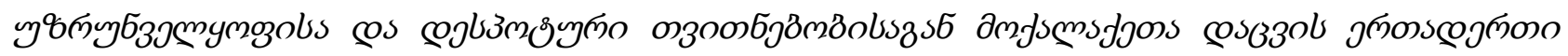
usə̋ysmgßss" (Mises 1944).

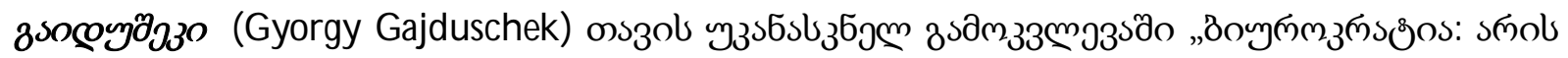

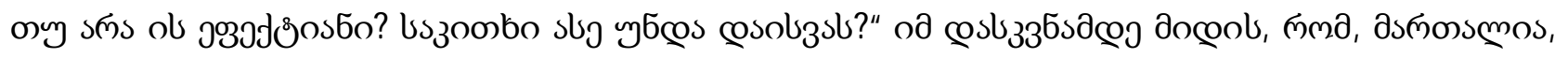

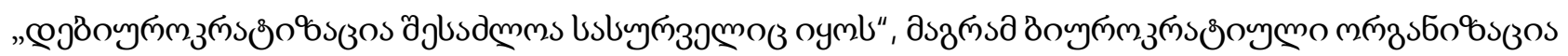

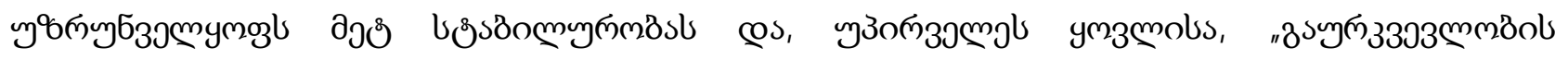

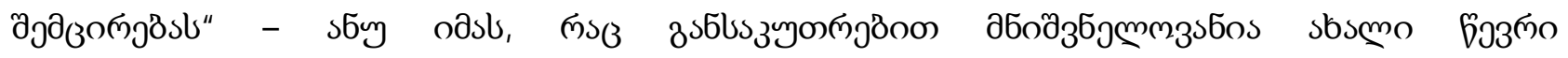

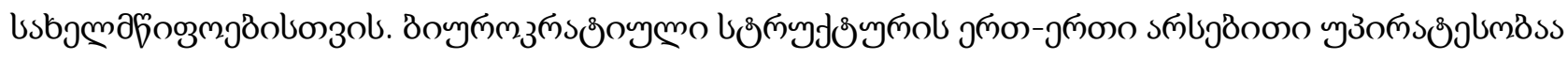

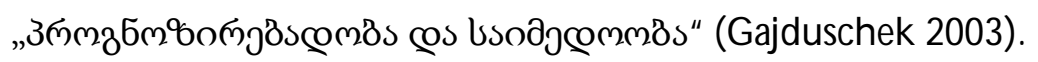

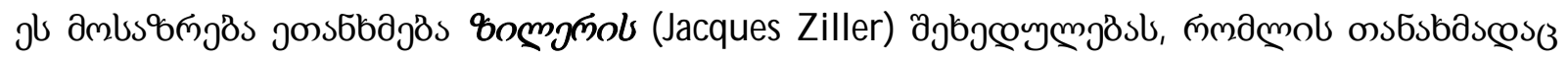

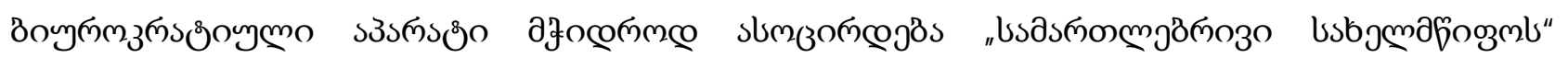

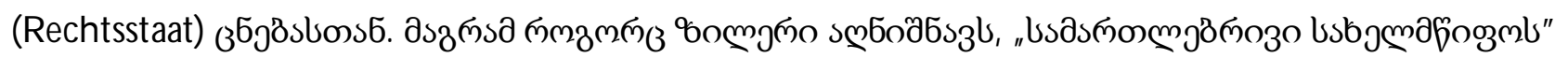

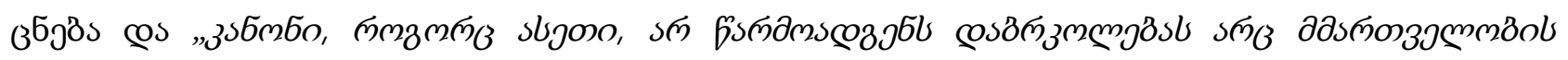

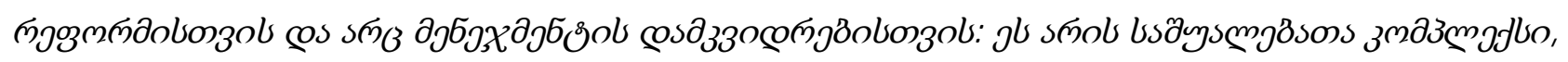

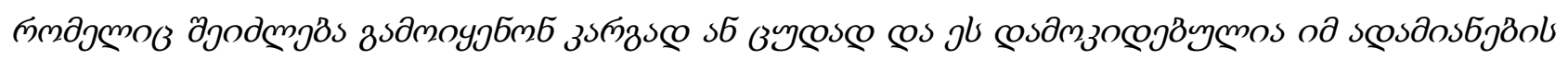

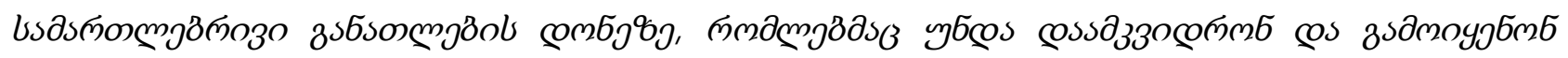

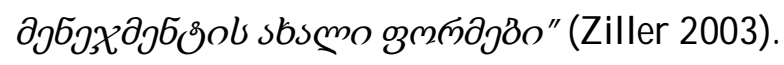

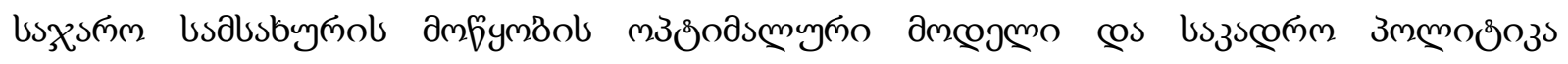

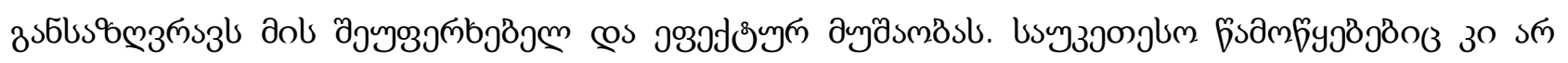
о б

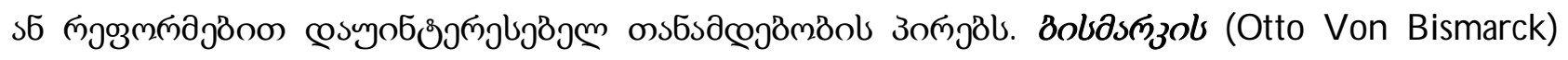

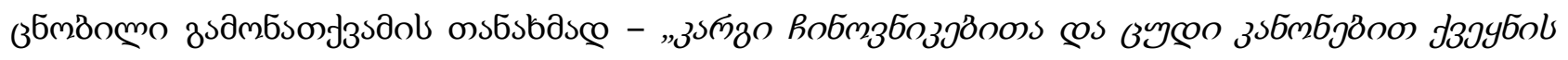

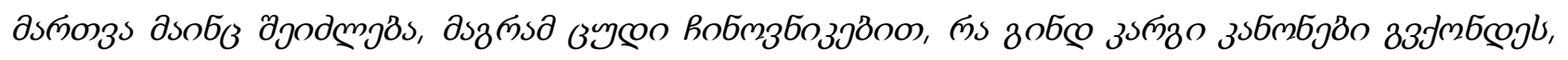

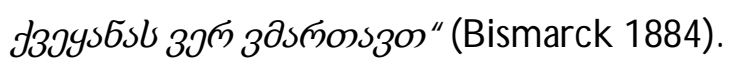




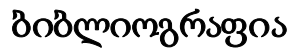

1. Clapham, C. 1982. 'Clientelism and the State', in Clapham, C. (ed.) (1982) Private Patronage and Public Power. Political Clientelism and the Modern State (London, Frances Pinter), pp. 1-35.

2. Dahlstrom, C., Lapuente V., Teorell J. 2011. Dimensions of bureaucracy II: A cross-national dataset on the structure and behaviour of public administration. QoG (The Quality of Government Institute) W orking Paper Series 2011:6.

3. Dimitrov, V., Goetz, K. H. and W ollmann, H. 2006. Governing after Communism. Institutions and Policymaking (Lanham, MD, Row man and Littlefield Publishers).

4. Eisenstadt, S. N. 1973. Traditional Patrimonialism and Modern Neopatrimonialism (Beverly Hills, CA, Sage Publications).

5. Eisenstadt, S. N. and Roniger, L. 1984. Patrons, Clients and Friends. Interpersonal Relations and the Structure of Trust in Society (Cambridge, Cambridge University Press).

6. Emerson, R. M. 1972. 'Exchange Theory, Part II: Exchange Relations and Networks.' pp. 58-87 in Sociological Theories in Progress, edited by J. Berger, M. Zelditch, and B. Anderson. Vol. 2. Boston: Houghton M ifflin.

7. Erdmann, G. and Engel, U. 2007. 'Neopatrimonialism Reconsidered: Critical Review and Elaboration of an Elusive Concept', Commonwealth and Comparative Politics, 45, 1, pp. 95119.

8. Erdmann, G. 2003: Neopatrimoniale Herrschaft - oder: Warum es in Afrika so viele Hybridregime gibt, in: Bendel, Petra et al. (eds.): Zwischen Demokratie und Diktatur. Opladen: Leske + Budrich, pp. 323-342

9. Evans, P. 1989. 'Predatory, developmental, and other apparatuses: a comparative political economy.' Sociological Forum 4(4): 561-587.

10. Fishman, R. M. 1990. 'Rethinking State and Regime: Southern Europe's Transition to Democracy', W orld Politics, 42, 3, pp. 422-40.

11. Geddes, B. 1999. 'W hat Do W e Know A bout Democratization After Twenty Y ears?'. Annual Review of Political Science, 2, pp. 115-44.

12. Hanson St. E. 2010. Post-Imperial Democracies: Ideology and Party Formation in Third Republic France, Weimar Germany, and Post-Soviet Russia. - Cambridge; N. Y.: Cambridge Univ. Press.

13. Hensell, S. 2009. Die W illkuËr des Staates. Herrschaft und Verwaltung in Osteuropa (W iesbaden, VSV erlag).

14. Hensell, S. 2012. The Patrimonial Logic of the Police in Eastern Europe, Europe-A sia Studies, $64: 5,811-833$

15. Kitschelt, H., Mansfeldova, Z., Markowski, R. \& Tor ka, G. 1999. Post Communist Party Systems. Competition, Representation, and Inter-Party Cooperation (Cambridge, Cambridge University Press).

16. M agal oni, B. 2006. V oting for Autocracy: Hegemonic Party Survival and its Demise in M exico. Cambridge: Cambridge University Press.

17. M igdal, J. S. \& Schlichte, K. 2005. 'Rethinking the State', in Schlichte, K. (ed.) (2005) The Dynamics of States. The Formation and Crises of State Domination (London, Ashgate), pp. 140.

18. Oleinik, A. (ed.). 2009. Reforming the State without Changing the Model of Power? On Administrative Reform in Post-Socialist Countries (London, Routledge).

19. Shelley, L. I. 1999. 'Post-Socialist Policing: Limitations on Institutional Change', in M awby, R. 
I. (ed.) (1999) Policing across the W orld. I ssues for the Twenty-first Century (London, UCL Press), pp. 75-87.

20. Verheijen, T. 2007. 'Public Administration in Post-Communist States', in Peters, B. G. \& Pierre, J. (eds) (2007) Handbook of Public Administration (Los Angeles, CA, Sage Publications), pp. 311-19.

21. W eber, M. 1947. The theory of social and economic organization. N ew Y ork: The Free Press.

22. W eber, M. 1958. The three types of legitimate rule. Berkeley Publications in Society and Instit utions, 4(1), 1-11.

23. W eber, M . 1978. Economy and Society. An O utline of Interpretive Sociology [edited by G. Roth $\&$ C. W ittich] (Berkeley, CA, University of California Press).

24. Гидденс, Э. 1999. Социология. М.

25. Фисун, А.А. 2010. К переосмыслению постсоветской политики: неопатримониальная интерпретация. - Политическая концептология. - № 4. - С. 158-187.

26. Эйзенштадт, Ш.Н. 2002. Парадокс демократических режимов: хрупкость и изменяемость (I) // Полис. №2. С.72-73. 


\section{Review and analysis of patrimonial and meritocratic governance concepts}

Tamar Charkviani

A ssociated Professor, Caucasus School of Humanities and Social Sciences Caucasus University, 1 Paata Saakadze Str. 0102, Tbilisi, Georgia

Web-site: www.cu.edu.ge

\section{Abstract}

A theoretical and methodological approach of the paper is the analysis of general neopatrimonial and social network theories - to understand both the dominant trend and variations in reform trajectories in Georgian civil service. This work introduces the concepts of neopatrimonialism, bureaucracy, meritocracy and informal networks examining their origins and defining characteristics. This is followed by consideration of the nature of the public sector in Georgia, exploring the implications of neopatrimonialism for public sector capacity and performance. In setting up the contrast between neopatrimonial and meritocratic bureaucracies, we have chosen to emphasize two points that lend themselves to relatively objective empirical assessment. The first is the importance of meritocratic recruitment, ideally based on some combination of education and examination, second is a predictable career ladder, which provides long term tangible and intangible rewards for those who have been recruited into the bureaucracy.

Key words: 'Civil Service', 'Bureaucracy', 'M eritocracy', 'Neopatrimonialism','Informal Networks' 